\title{
MULTIFUNCTIONAL PROPERTIES OF CHICKEN EMBRYONIC PRENATAL MESENCHYMAL STEM CELLS- PLURIPOTENCY, PLASTICITY, AND TUMOR SUPPRESSION
}

\author{
Bhuvanalakshmi G ${ }^{1}$, Frank Arfuso ${ }^{2,3}$, Arun Dharmarajan ${ }^{2}$, and Sudha Warrier ${ }^{1,2, *}$ \\ 1) Division of Cancer Stem Cells and Cardiovascular Regeneration, Manipal Institute of \\ Regenerative Medicine, Manipal University, Bangalore - 560 065, INDIA \\ 2) School of Biomedical Sciences, Faculty of Health Sciences, Curtin University, Perth,
}

Western Australia, 6845

3) School of Anatomy, Physiology and Human Biology, The University of Western Australia, Perth, Western Australia, 6009

* Corresponding author-email: sudha.warrier@gmail.com; sudha.warrier@manipal.edu 


\section{ABSTRACT}

The chick embryo represents an accessible and economical in vivo model, which has long been used in developmental biology, gene expression analysis, and loss/gain of function experiments. In the present study, we assessed and characterized bone marrow derived mesenchymal stem cells from prenatal day 13 chicken embryos (chBMMSCs) and determined some novel properties. After assessing the mesenchymal stem cell (MSC) properties of these cells by the presence of their signature markers (CD 44, CD 73, CD 90, CD 105, and vimentin), we ascertained a very broad spectrum of multipotentiality as these MSCs not only differentiated into the classic tri-lineages of MSCs but also into ectodermal, endodermal, and mesodermal lineages such as neuron, hepatocyte, islet cell, and cardiac. In addition to wide plasticity, we detected the presence of several pluripotent markers such as Oct4, Sox2, and Nanog. This is the first study characterizing prenatal chBMMSCs and their ability to not only differentiate into mesenchymal lineages but also into all the germ cell layer lineages. Furthermore, our studies indicate that prenatal chBMMSCs derived from the chick provide an excellent model for multi-lineage development studies because of their broad plasticity and faithful reproduction of MSC traits as seen in the human. Here, we also present evidence for the first time that media derived from prenatal chBMMSC cultures have an antitumorigenic, anti-migratory, and pro-apoptotic effect on human tumors cells acting through the Wnt-B-catenin pathway. These data confirm that chBMMSCs are enriched with factors in their secretome that are able to destroy tumor cells. This suggests a commonality of properties of MSCs across species between human and chicken.

Key words- Mesenchymal stem cells, chicken, pluripotency, tumor suppression, multilineage differentiation

\section{Running title: Prenatal chicken MSCs are pluripotent and anti-tumorigenic}




\section{INTRODUCTION}

Bone marrow derived mesenchymal stem cells (BMMSCs) can be differentiated into distinct skeletal tissues both in vitro and in vivo. Understanding the molecular mechanisms controlling stem cell differentiation is imperative for further progress in tissue and organ regeneration. The chicken embryo has traditionally been a favorite model of developmental biologists and cancer biologists, and has been used a platform to study stem cell implantation and differentiation in vivo. Being a versatile animal model, the chicken embryo has been used extensively for xenotransplantation studies of human stem cells from multiple sources. Human dental pulp stem cells, after transplantation into the mesencephalon region of the chicken embryo, expressed neuronal markers and acquired typical neuronal morphology [1]. Similarly, human-derived hematopoietic stem cells [2], olfactory mucosa stem cells [3], embryonic stem cells [4], and mesenchymal stem cells [5] have been shown to differentiate into multiple lineages when transplanted into the chicken embryo. In addition, the chicken embryo has also been used to study cell-to-cell interactions between human skin-derived stem cells and glioma cells [6]. Thus, the success of using the chicken embryo as an efficient xenotransplantation platform for studying human stem cell biology can be attributed to easy handling, accessibility to surgical implantation methods, and a lack of an advanced immune system.

Khatri et al. [7] characterized chicken lung mesenchymal stromal cells and studied their susceptibility to avian influenza virus. A genetic marker, namely, deleted-in-azoospermia-like (DAZL), was conserved in primordial germ cells (PGCs) and during germ-line differentiation until the adult stage, making them a valuable molecular marker for studies of PGC differentiation and germ-line development in the chicken [8]. However, the earliest MSCs to have been studied from the chicken are neonatal BMMSCs from 1-14 day old chickens [7]. A 
comprehensive study of the BMMSCs from chicken embryos has not been performed so far. Therefore, in this study we not only profiled the characteristic stem cell features of BMMSCs derived from prenatal chicken embryos (chBMMSCs), but also explored their plasticity in order to evaluate the plethora of lineages into which stem cells obtained from an early developmental stage can transform. We also identified a very interesting property of antitumorigenicity in these chBMMSCs. This study will help in validating chick-derived prenatal stem cells as a highly robust and flexible platform for multiple lineage commitment and differentiation studies.

\section{METHODS}

\section{ISOLATION AND EXPANSION OF chBMMSCs}

Chick embryos of 12-13 days (obtained from Veterinary College, Bangalore, India, after approval by the Institutional Ethics Committee) were opened from the shell, and bone marrow was collected from the femur by flushing with stem cell growth medium containing DMEM with high glucose (Gibco) supplemented with 1X GlutaMAX (Life Technologies), 10\% Fetal Bovine Serum (FBS) (Hyclone), and 100U/mL PenStrep (Life Technologies) using a sterile syringe. The aspirated bone marrow cells were centrifuged twice at $1500 \mathrm{rpm}$ for $10 \mathrm{~min}$ in fresh growth medium, and plated at a density of $1 \times 10^{6}$ cells $/ \mathrm{ml}$. The cultures were incubated at $37^{\circ} \mathrm{C}$ in a humidified atmosphere containing $5 \% \mathrm{CO}_{2}$. The floating cells were initially removed at intervals of $12-24 \mathrm{~h}$ and the cells were characterized for the colony forming ability typical of mesenchymal stromal cells. The colony forming units (CFUs) were identified by staining with $0.1 \%$ crystal violet, and culture medium was changed every day until confluence was reached. Expansion of chBMMSCs was performed as previously reported for MSCs derived from the human amniotic membrane [9]. Briefly, after reaching confluence, P0 cells were trypsinized using 1\% trypsin-EDTA (Invitrogen) and the cells were 
passaged till P4 to obtain a homogenous population. The cells at P3 were characterized further and used for subsequent experiments.

\section{GROWTH CURVE ANALYSIS AND POPULATION DOUBLING TIME}

Chick BMMSCs at p3 were plated at 1000 cells/well in a 96 well plate and a growth curve was determined by using an MTT assay (Trevigen) at different time points $(1,2,3,4$, and 5 days). From the growth curve, the population doubling time was determined [10].

\section{MULTI-LINEAGE DIFFERENTIATION}

At the third passage, chBMMSCs were induced to differentiate into the classic tri-lineage of MSCs; namely osteogenic, adipogenic, and chondrogenic, and into the representative lineages of the three germ layers; namely neuronal, cardiac, hepatic, and islet cell using previously described protocols as follows.

Adipogenesis induction medium contained $1 \mu \mathrm{mol} / \mathrm{L}$ dexamethasone (Sigma-Aldrich), 10 $\mu \mathrm{g} / \mathrm{ml}$ insulin (Clonetics), and $100 \mu \mathrm{mol} / \mathrm{L}$ indomethacin (Sigma-Aldrich) [11]. Osteogenesis induction medium consisted of $0.1 \mu \mathrm{mol} / \mathrm{L}$ dexamethasone (Sigma-Aldrich), $0.2 \mathrm{mmol} / \mathrm{L}$ ascorbic acid (Clonetics), and $10 \mathrm{mmol} / \mathrm{L}$ glycerol 2-phosphate (Sigma-Aldrich) [12]. Chondrogenesis was induced by $0.2 \mathrm{mmol} / \mathrm{L}$ ascorbic acid 2-phosphate solution (Clonetics), $0.1 \mu \mathrm{mol} / \mathrm{L}$ dexamethasone (Sigma-Aldrich), $0.1 \mathrm{mmol} / \mathrm{L}$ non-essential amino acid (HiMedia), and 1mM sodium pyruvate (Sigma-Aldrich) [13]. Within 2-3 days, morphological changes into the tri-lineages were observed and adipocytes, osteocytes, and chondrocytes were fixed and stained with Oil Red O Solution (0.5\%), Von Kossa Solution (2.5\%), and 1\% Alcian Blue solution (all from Sigma-Aldrich) respectively and visualized under a bright field phase contrast microscope (Nikon- Eclipse TE 2000-S). Photographs were taken using Qimaging- QICAM-fast 1394. 
Hepatogenic differentiation was performed by treating chBMMSCs with hepatic induction medium consisting of $20 \mathrm{ng} / \mathrm{mL}$ bFGF (Clonetics), $0.5 \mu \mathrm{M}$ dexamethasone (Sigma-Aldrich), and $50 \mathrm{mg} / \mathrm{mL}$ insulin transferrin selenium (ITS) (Invitrogen) [14]. Islet differentiation was performed according to a reported protocol [15] wherein induction medium consisted of $10 \mathrm{mM}$ nicotinamide (Sigma-Aldrich), 2.5mM mercaptoethanol (Sigma-Aldrich), and $2.5 \mathrm{mM}$ glucose (Hi-media). Neuronal induction was performed using 10ng/ml bFGF (Clonetics) [16, 17], $0.5 \mu \mathrm{M}$ retinoic acid (Sigma-Aldrich), and $1 \mathrm{mM} \mathrm{B-mercaptoethanol} \mathrm{(Sigma-Aldrich).}$ Cardiac differentiation was achieved using an induction medium containing $10 \mu \mathrm{m}$ 5azacytidine [18]. In all cases, the morphological changes appeared within 3-4 days. Hepatic cells and islets were fixed and stained with $0.5 \%$ Periodic acid-Schiff stain (PAS) and 100X Dithiazone (DTZ) (Sigma-Aldrich) respectively, and visualized under a bright field phase contrast microscope (Nikon- Eclipse TE 2000-S). Neuronal and cardiac cells were fixed for immunolocalization using mAbs for Nestin (1:250 dilution) and GATA4 (1:250 dilution) (BD Biosciences) respectively.

\section{IMMUNOCYTOCHEMISTRY}

Cells from passage P3 were grown in 4-chambered slides and fixed using 4\% paraformaldehyde for $20 \mathrm{~min}$ at $4^{\circ} \mathrm{C}$, and blocked with $3 \%$ bovine serum albumin (BSA) in PBS for $30 \mathrm{~min}$ at room temperature. The cells were then incubated for $1 \mathrm{~h}$ in dark conditions at $4^{\circ} \mathrm{C}$ with primary non-labeled mouse anti-human antibodies against vimentin, $\mathrm{CD} 73, \mathrm{~B}-3$ tubulin, insulin receptor, troponin I, GATA4, Oct4, and Sox2 (1:250 dilutions, BD Biosciences) followed by anti-mouse rabbit fluorescein isothiocyanate (FITC) or phycoerythrin (PE) labeled secondary antibodies (1:250 dilutions, Invitrogen) for $1 \mathrm{~h}$ at $37^{\circ} \mathrm{C}$. An additional step was included for staining the intracellular, nuclear, or cytoskeletal markers (vimentin, B-3-tubulin, insulin receptor, Troponin T, GATA4, Oct4, and Sox2) by washing 
the cells with PBS containing $0.05 \%$ Tween-20 along with the treatment of cells using $3 \%$ BSA containing $0.1 \%$ Triton $\mathrm{X} 100$ for $30 \mathrm{~min}$ at room temperature to ensure that cell permeability was achieved. The nuclear stain 4',6-diamidoino-2-phenylindole (DAPI) (1:10000 dilution) was used for nuclear visualization and a drop of anti-fade (Vectashield; Vector Laboratory, Burlingame CA, USA) was added to avoid quenching of the fluorochrome before placing the cover slip. The slides were visualized using a Nikon Eclipse TE2000-U fluorescent microscope and photographs were taken using Qimaging- QICAMfast 1394.

\section{FLOW CYTOMETRY}

Chick BMMSCs at P3 were removed from the culture dish with 0.05\% Trypsin- EDTA, the cell suspension was centrifuged at $1000 \mathrm{rpm}$ for $10 \mathrm{~min}$ and washed twice with PBS. Cells were fixed in pre-chilled $70 \%$ ethanol and incubated in mouse anti-human FITC labeled antibodies against CD73, CD90, and CD34 (1:100 dilution) (all antibodies were purchased from Becton Dickenson, San Diego, CA, USA) for 1h on ice. The cells were acquired using BD-FACS Calibur flow cytometer with a 488nm laser and data were analyzed by Cell Quest Software (Becton Dickinson, San Jose, CA, USA).

\section{SEMI-QUANTITATIVE REVERSE TRANSCRIPTION-PCR:}

RNA Isolation, cDNA Synthesis, and Quantitative reverse transcription PCR.

Total RNA was extracted from chBMMSCs and the human primary glioblastoma U87-MG cell line using the RNeasy Plus Mini kit (Qiagen) according to the manufacturer's instructions. One microgram of total RNA was reverse-transcribed using SuperScript III First-Strand Synthesis System (Invitrogen, Carlsbad, CA). One microgram of total RNA was mixed with $1 \mu \mathrm{L}$ Oligo dT $(50 \mu \mathrm{M})$ and $1 \mu \mathrm{L}$ of $\mathrm{dNTP}(10 \mathrm{mM})$ and made to $13 \mu \mathrm{L}$ with 
DEPC treated water and heated at $65^{\circ} \mathrm{C}$ for 10 minutes, followed by incubation on ice. After primer hybridisation, $7 \mu \mathrm{L}$ reaction volume containing $5 \mathrm{X}$ first strand buffer, RNase OUT (40U/ $\mu \mathrm{L}), 0.1 \mathrm{M} \mathrm{DTT}$, and Superscript III were added to the RNA and subjected to thermocycling $\left(25^{\circ} \mathrm{C}, 5 \mathrm{~min} ; 50^{\circ} \mathrm{C}, 60 \mathrm{~min} ; 70^{\circ} \mathrm{C}, 15 \mathrm{~min}\right)$ in a Veriti 96 well thermal cycler (Applied Biosystems). Qualitative expression of chicken-specific mesenchymal stem cell markers, lineage differentiation markers, and apoptotic markers (primers from Sigma, sequence as indicated in Tables 1 and 2$)$ were analyzed by $\mathrm{PCR}\left(95^{\circ} \mathrm{C} \mathrm{30s}\right.$; annealing temperature, $30 \mathrm{~s} ; 72^{\circ} \mathrm{C} 30$ s for 40 cycles) in a Veriti 96 well thermal cycler. Products were separated by $1.5 \%$ agarose gel electrophoresis and detected using ethidium bromide. Integrated density values (IDV) were calculated using Alpha manager.

\section{REAL-TIME QUANTITATIVE REVERSE TRANSCRIPTION-PCR.}

The qualitative results of mRNA expression were further quantified using iQ SYBR Green Supermix (Bio-Rad, Hercules, CA) in a real time PCR system. cDNAs and gene-specific primers were mixed with $2 \mathrm{X}$ iQ SYBR Green Supermix (Bio-Rad), and dispensed on a MicroAmp® Optical 8-Tube Strip. Fluorescence shift was observed using a 7500 Real-time PCR system (Applied Biosystems). Reaction parameters were $50^{\circ} \mathrm{C}$ for 2 minutes, $95^{\circ} \mathrm{C}$ for 10 minutes, followed by 40 cycles of $95^{\circ} \mathrm{C}$ for 15 seconds and $60^{\circ} \mathrm{C}$ for 1 minute. The relative abundance of mRNAs was obtained using the comparative cycle threshold method and was normalized to the housekeeping control GAPDH. Results are also expressed as fold changes in the mRNA levels of a gene compared to the treated or untreated samples.

\section{ANTI-TUMORIGENICITY ANALYSIS:}

\section{MTT assay:}


The TACS MTT assay kit (R\&D Systems) was used according to the manufacturer's protocol prepared by collecting the medium in which the cells were cultured at $\mathrm{P} 0, \mathrm{P} 1, \mathrm{P} 2$, and $\mathrm{P} 3$, and centrifuging at $1500 \mathrm{rpm}$ to remove cell debris. The medium was stored at $-20^{\circ} \mathrm{C}$ till use. The U87 (U87-MG grade 4 glioblastoma) and Hep2 (Human Larynx carcinoma) cell lines were obtained from ATCC and cultured and maintained in DMEM/F-12 (Gibco) (1:1) containing 1X GlutaMAX (Life Technologies), 10\% Fetal Bovine Serum (Hyclone), and 100U/mL PenStrep (Life Technologies). Non-stem cell controls used were human fibroblasts and mouse embryonic fibroblasts obtained from primary cultures. 10,000 cells per well were plated in a flat-bottomed 96-well plate. After 12 hours, they were given a medium change and chBMMSC conditioned medium from P0, P1, P2, and P3 was added to the plates and incubated for $24 \mathrm{~h}$. Following treatment, cells were washed with 1X PBS and provided with 100uL of fresh basal medium (DMEM/F-12 + DMEM-LG) along with 10uL of MTT. Samples were incubated for 3 hours at $37^{\circ} \mathrm{C}$ and $5 \% \mathrm{CO}_{2}$. The dye was solubilized by the addition of $100 \mathrm{uL}$ detergent reagent and an overnight incubation in the dark at RT, and the plates were read at $595 \mathrm{~nm}$ using a Victor 3 Multilabel Plate Reader (Perkin-Elmer).

\section{BrdU assay}

Cancer cells were treated with BMMSC-CM as indicated previously. Cell proliferation was measured using the BrdU Cell Proliferation Assay Kit (Cell Signalling Tech Inc) according to the manufacturer's protocol. Plates were read at $450 \mathrm{~nm}$ using a Victor 3 Multilabel Plate Reader.

\section{Caspase-3 assay}

U87 cells were treated with BMMSC-CM as indicated previously. The activity of apoptosisinducing caspase-3 was assayed using the EnzChek DEVD-CHO Caspase3 Assay Kit (Invitrogen), which provides a fluorescent substrate R110. The intensity of the fluorescence is 
correlated with an increase in caspase-3 activity. The fluorescence intensity was measured using a Victor 3 Multilabel Plate Reader at 485/535 nm (Ex/Em).

\section{Western blotting}

Protein expression levels of $\beta$ catenin, the downstream and central component of canonical Wnt signaling, was determined by Western blotting. After treatment of U87 cells with BMMSC-CM, total protein in each condition was isolated in RIPA buffer (Invitrogen) following the manufacturer's instructions. Western blots contained 40 ug of protein per lane on a $8 \%$ Tris-glycine SDS-polyacrylamide gel. Proteins were transferred to a PVDF membrane (GE, NJ, USA). Blots were blocked in PBS containing 5\% nonfat dry milk powder and incubated overnight at $4{ }^{\circ} \mathrm{C}$ with either anti-human mouse $\beta$-catenin mAbs 1:500 dilution (R \& D Systems, MN, USA), or anti- human mouse phospho ß-catenin mAbs 1:500 dilution ( $\mathrm{R} \&$ D Systems, MN, USA) or anti-human mouse GAPDH mAbs 1:500 dilution (Millipore). Rabbit anti-mouse Horse Radish Peroxidase linked secondary antibodies (1: 3000) were used to bind to the primary antibody. The blot was developed with enhanced chemiluminescence reagent (Pierce, IL) and images were captured using AlphaImager (CA, USA).

\section{Wound scratch assay:}

U87 cells were grown in 6-well plates at a density of $3 \times 10^{6} / \mathrm{mL}$, and a small linear scratch was created in the confluent monolayer by gently scraping with a sterile cell scraper as per standard methods [19]. Cells were extensively rinsed with medium to remove cellular debris and treated with BMMSC-CM at passage 2. The area of the wound at selected time points $(0$, 12,24 , and 48 hours) was recorded to assess migration and wound healing using a bright field phase contrast microscope (Nikon- Eclipse TE 2000-S) and photographs were taken using Qimaging- QICAM-fast 1394. The experiments were repeated thrice. 


\section{In vitro angiogenesis assay:}

The effect of BMMSC-CM on capillary tube formation of U87 cells was investigated using an In-vitro angiogenesis assay kit (Millipore, USA) according to the manufacturer's instructions. The formation of capillary tubes by the glioma cell line U87 in Matrigel has been previously demonstrated [20] .Briefly, 10000 cells/well were seeded on a ECMatrix gel pre-coated 96-well plate and treated with either control medium or BMMSC-CM. Before seeding, U87 cells were treated with either control medium or BMMSC-CM for 24h, and equal numbers of cells were added for both control and BMMSC-CM U87 cells. To study for the disruption of the capillary tubes, U87 cells were first directly seeded in the ECMatrix in control medium. After the formation of capillary tubes after $8 \mathrm{~h}$, medium was replenished either with control medium or BMMSC-CM. Capillary tube formation was quantified at 4, 8 , 12, and $24 \mathrm{~h}$ by bright field phase contrast microscope (Nikon- Eclipse TE 2000-S) and photographs were taken using Qimaging- QICAM-fast 1394. The experiments were repeated thrice.

\section{In vitro migration assay:}

Cell migration was analyzed using a Transwell Migration System (BD Biosciences). Briefly, U87 cells were plated into upper chambers (Transwells with $8.0 \mu \mathrm{m}$ pore size) in normal U87 culturing medium. The lower compartment of the chamber contained regular medium or BMMSC-CM. The chambers were cultured at $37^{\circ} \mathrm{C}$ in $5 \% \mathrm{CO}_{2}$ for 12 hours. The filter membranes were removed and the cell migrated to the lower surface were fixed with $70 \%$ ethanol and stained with $H \& E$ and visualized under a phase contrast microscope. The experiments were done in triplicates.

\section{STATISTICAL ANALYSIS}


Data represent mean and SE from experiments done in triplicate. Each experiment was repeated three times. A two-sided Student's t test was used to determine the significance of any differences. For all statistical analyses, the level of significance was set at a probability of $<0.05(* \mathrm{p}$ value $<0.05)$

\section{RESULTS}

\section{PRENATAL chBMMSCS PROLIFERATE RAPIDLY AND EXPRESS CHARACTERISTIC MSC MARKERS}

Primary cells isolated from the 13-14 day prenatal chick bone marrow adhered in large numbers and elongated after $12 \mathrm{~h}$, and formed rapidly dividing colony forming units (CFUs) within 48h (Fig 1a). Cells proliferated rapidly and doubled in their numbers from their initial seeding density within $24 \mathrm{~h}$ (Fig 1b). After about 2 days the cells exhibited characteristic fibroblastic morphology and obtained 90\% confluence. These cells were passaged up to P2 and were then analyzed for characteristic MSC markers by immunofluorescence, flow cytometry, and semi-quantitative PCR. They were positive for CD 73, CD 90, CD 105, and vimentin, but negative for CD34 and CD45 (Fig 1c-e).

\section{ChBMMSCS ARE ABLE TO RAPIDLY DIFFERENTIATE INTO ECTODERMAL, MESODERMAL, AND ENDODERMAL LINEAGES}

Upon induction with the respective factors, chBMMSCs underwent differentiation into the MSC tri-lineage of adipocyte, chondrocyte, and osteocyte cell types within $24 \mathrm{~h}$ (Fig 2a, b, and c). These cells stained positively with oil red O stain for adipocytes (Fig 2a), saffranin orange for chondrocytes (Fig 2b), and silver stain for osteocytes (Fig 2c). Upon testing for differentiation into the non-mesenchymal lineages, they were found to efficiently differentiate into the endodermal lineages of hepatic and islet-like cell types (Fig $2 \mathrm{~d}$ and e). 
Hepatic differentiation was confirmed by morphology (Fig 2d1) and the cells staining bright pink, showing positivity for Periodic Acid- Schiff (PAS) stain (Fig 2d2). Islet-like differentiation was determined morphologically by the appearance of islet-like clusters (Fig 2e1), immunohistochemical staining for insulin receptor (IR) (Fig 2e2), and DTZ-specific crimson red staining (Fig 2e3). Undifferentiated chBMMSCs did not stain for IR (Fig 2e4), confirming the absence of islet cells in the native chBMMSCs. The endodermal lineage differentiation was achieved as early as $48 \mathrm{~h}$. Ectodermal lineage development was confirmed by neuronal differentiation in which the cells obtained neuronal morphology with elongated axons (Fig 2f1) and stained positively for the neuronal marker $\beta-3$ tubulin, as confirmed by immunohistochemistry (Fig 2f2). Undifferentiated chBMMSCs did not stain for B-3 tubulin (Fig 2f3), confirming the absence of neuronal cells in the native chBMMSCs. Cardiac differentiation was confirmed by morphology (Fig $2 \mathrm{~g} 1$ ), the presence of the early cardiac induction nuclear marker GATA4 (Fig 2g2), and the late cardiac structural marker, troponin I (Fig 2g3). Undifferentiated chBMMSCs did not stain for troponin I (Fig 2g4). Both neuronal and cardiac morphology was seen within 3 days of induction, indicating highly efficient plasticity of these MSCs. The ability to differentiate into neuronal, cardiac, hepatocyte, and islet cell types was confirmed by RT-PCR ( Fig 2h) of specific markers; namely, glial fibrillary astrocyte protein (GFAP) for neuronal, $\alpha$ myosin heavy chain ( MHC) for cardiac, GATA4 for hepatocyte, and Isl1 for islet cell differentiation.

\section{chBMMSCs EXPRESS PLURIPOTENCY MARKERS}

The early embryonic markers were identified by the localization of embryonic stemnessrelated transcription factors such as Oct4 and Sox 2 in the nucleus (Fig 3a1, 2 and b1, 2). The mRNA expression of pluripotent markers Oct4, Sox2, and Nanog along with the characteristic MSC marker CD44 was confirmed by qPCR analysis (Fig 3c). This indicates 
that these MSCs are primitive and have still retained their pluripotent properties. Normal human fibroblasts, used as a negative control, did not express any pluripotent markers (Fig $3 c 3$ ). In order to demonstrate the loss of pluripotency upon differentiation, we analyzed the expression of Oct4, Sox2, and Nanog, before and after differentiation to the adipogenic lineage. There was a clear loss of expression of these markers (Fig 3c4), confirming that these markers are only present in undifferentiated stem cells.

\section{BMMSC CONDITIONED MEDIA SUPPRESSES GROWTH OF GLIOMA AND HEAD AND NECK CANCER CELLS, PREVENTS CELL MIGRATION AND INHIBITS ANGIOGENESIS}

In this study, we report for the first time the ability of secreted factors from chBMMSC culture media to inhibit tumor cell proliferation, migration, and angiogenesis. Conditioned medium of chBMMSCs (BMMSC-CM) at passage 2 was able to inhibit $50 \%$ of the proliferation of the glioma cell line U87 as determined by MTT assay (Fig 4a). This inhibition was not seen when we used the conditioned media of normal human fibroblast cells or mouse embryonic fibroblasts (Fig 4 b). This inhibitory effect was further confirmed using a BrdU assay, which indicated a marked reduction in newly synthesized DNA when U87 cells were grown in BMMSC-CM (Fig 4d). We wanted to investigate if the inhibition by BMMSC-CM could be seen in different tumor lines and tested its effects on the head and neck cancer line Hep2. Growth inhibition, studied by MTT and BrdU assays, was similar to that seen with U87 cells and, over a period of 48h, Hep2 cellular growth was completely $\operatorname{arrested}(\mathrm{Fig} 4 \mathrm{c}$ and $\mathrm{d})$.

To analyze the action of this inhibition of BMMSC-CM, we examined the activity of apoptosis-inducing caspase 3, using a caspase-3 assay. Apoptosis was induced in U87 cells treated with BMMSC-CM, which was evidenced by increased caspase-3 activity (Fid 4e). 
Further, to obtain insights into the inhibitory mechanisms, we utilized activators of the Wntß-catenin pathway. Lithium chloride, an inhibitor of GSK-3ß kinase and agonist Wnt3a, both activators of $\beta$-catenin, abolished the inhibition by BMMSC-CM. Using an antibody against sFRP4, a known antagonist of Wnt-Frizzled-related binding protein (Frb) [21], also increased proliferation of BMMSC-CM treated U87 cells ( Fig 4f). These results clearly suggest that the mode of inhibition is through the Wnt- $\beta$-catenin pathway.

Conditioned medium was seen to have classic anti-tumor activity as assessed by migration and angiogenesis assays. Migration of U87 cells, as assessed by a wound scratch assay, was inhibited by BMMSC-CM (Fig 5a-d). Even after $24 \mathrm{~h}$, the wounded area was not covered when treated with chBMMSC conditioned medium (Fig 5c), and, after 48h, the cells started undergoing apoptosis (Fig 5d). To further confirm inhibition of migration by BMMSC-CM, a migration assay was performed using a transwell migration system. We observed a marked inhibition of migration of U87 cells across the membrane by BMMSC-CM (Fig 5e), as observed by reduced $\mathrm{H} \& \mathrm{E}$ staining of the membrane in BMMSC-CM treated wells in comparison to the control. Angiogenesis, the hallmark property of aggressive tumors, was studied using an in vitro angiogenesis assay (Fig 6a-e). The classic angiogenic ring formation by U87 cells was retarded by BMMSC-CM in which the cells formed clumps, even after $24 \mathrm{~h}$ incubation on an angiogenesis promoting matrix (Fig 6e). Additionally, angiogenic rings formed by U87 cells within 8h were disrupted upon incubation with BMMSC-CM for 24h (Fig 6f), demonstrating a clear inhibition of capillary tubes, whereas control medium further enhanced the tube formation after $24 \mathrm{~h}$.

BMMSC CONDITIONED MEDIA INHIBITS GLIOMA CELLS ACTING THROUGH THE WNT- B-CATENIN PATHWAY 
Expression of apoptotic genes and genes downstream of the Wnt- $B$-catenin TCF-LEF axis were studied. qPCR analysis of downstream activators of TCF-LEF linked to apoptosis and proliferation (Bax, caspase-3, xIAP, p21, and CyclinD1), metastasis (MMP2), and angiogenesis (VEGF) was performed. Apoptotic markers, p21, Bax, and caspase 3 were induced in BMMSC-CM treated U87 cells (Fig 7a, b), whereas expression of angiogenic gene (VEGF), ECM specific gene (MMP2), inhibitor of apoptosis gene (xIAP), and proproliferation gene (CyclinD1) decreased (Fig 7a, b ). A confirmatory role of B-catenin being the target of inhibition by BMMSC-CM was provided by Western blot analysis, wherein $B$ catenin, although present in untreated U87 cells, was reduced in BMMSC-CM treated U87 cells. In contrast, inactive phospho ß-catenin was only detected in BMMSC-CM treated U87 cells, further confirming the role of $\beta$-catenin in inhibition (Fig 7c).

\section{DISCUSSION}

In this study, we have characterized chicken BMMSCs for the first time in their embryonic stage, that is, from prenatal bone marrow. We show that these MSCs are extremely pliable and plastic, and have a very high turnover rate. Unlike MSCs isolated from adult human tissues, chBMMSCs were able to differentiate into all lineages of the ecto-, meso-, and endodermal types at a very rapid rate upon induction. Furthermore, we provide evidence that the media in which these MSCs are grown have a potent anti-tumorigenic effect by promoting apoptosis. This is the first time that MSCs from a non-mammalian organism have been shown to possess an anti-tumorigenic potential, indicating that stem cells have a property to detect and curb uncontrolled proliferation, and that this is probably a universal feature of mesenchymal stem cells.

Bone marrow MSCs from the chick have been characterized initially from the 1-14 days old chicken [7] and from adult chicken [22]. MSCs from chick embryo bone marrow stromal 
cells have been demonstrated to differentiate into bone and cartilage tissue when grown in a three-dimensional polymer scaffold [23]. However, a broad differentiation potential and a pluripotentiality of early chick embryo BMMSCs has not been demonstrated so far. In our study, we have isolated BMMSCs from prenatal chicken and found them to have a very rapid turnover time of $24 \mathrm{~h}$, which identifies these as one of the fastest proliferating MSCs [24]. This could be attributed to their stage in very early development during the process of organogenesis, when a high turnover of stem cells is required to build the organs for completing development. On further characterization of these MSCs, we found them to be completely similar to human BMMSCs in relation to their marker profile and stemness properties. This suggests that chBMMSCs are an attractive source of MSCs in which isolation and proliferation is extremely rapid and can be obtained with minimum ethical constraints in comparison to human tissues. Additionally, we also demonstrated that chBMMSCs could differentiate into a wide variety of cell types in addition to the classic trilineage of adipocyte, chondrocyte, and osteocyte cell types. These MSCs differentiated upon induction into all the lineages we tested; namely, neuronal, cardiac, hepatic, and islet-like cells. Their duration of induction was much shorter than previously reported for any MSCs, with most lineages showing the early differentiation markers within 3-4 days of induction. This extreme plasticity could be attributed to the early developmental stage from which they were obtained, a property which could be exploited for studying the molecular regulation of lineage differentiation using a short time span. Bone marrow derived MSCs are plastic entities equipped with the ability to adjust to new mircoenvironments. However, this ability is limited in the adult tissue and is mostly confined to differentiation into the classic tri-lineage of mesodermal types such as osteogenic, adipogenic, and chondrogenic [25]. The wide spectrum of differentiation ability exemplified by the embryonic BMMSC, which we observed in this study, suggests that they share a similarity to embryonic stem cells with 
respect to their plasticity. Furthermore, since these BMMSCs are obtained from an early developmental stage, they are still naïve to new environs and are not lineage imprinted as seen with mesenchymal stromal cells derived from adult tissues [26]. These chick BMMSCs could thus be used as an ideal model for testing developmental toxins affecting the differentiation process of neuronal, cardiac, and hepatic lineages.

In chick BMMSCs isolated from early neonates, a pluripotent nature has been attributed to these MSCs [7]. This corroborates well with our study wherein we demonstrate the nuclear localization of Oct4 and Sox2, and mRNA expression of these markers, together with Nanog and CD44, and the loss of the pluripotent markers upon differentiation. The expression of pluripotency markers is probably related to the fetal or prenatal stage from which they are isolated and which bears resemblance to the embryonic stem cells. In contrast, adult BMMSCs of chicken, dermal-derived chicken MSCs, MSCs derived from chicken umbilical cord Wharton Jelly [20, 27], or human fibroblasts, as observed in our study, have not been shown to express pluripotency or embryonic markers. Pluripotent stem cells are capable of differentiating into all embryonic germ layers and pluripotentiality is characterized by the expression of key pluripotent markers Oct4, Sox2, and Nanog [28, 29]. These markers can be induced by reprogramming or can occur naturally as seen in embryonic stem cells (ESCs). The expression of key pluripotent genes in chick embryonic BMMSCs, as seen in our study, further strengthens the notion that these stem cells are similar to ESCs. Detailed comparative studies between chick embryo BMMSCs and chick ESCs will throw light on the degree of pluripotentiality of these two stem cell types.

Some of the most attractive properties of MSCs are their inherent ability to track tumor cells [30] and their innate anti-neoplastic properties [31]. Our observation of the anti-tumor ability of chBMMSCs further confirms another property of MSCs, i.e. the ability to secrete factors 
that are apoptotic to tumor cells. Thus, the chBMMSC secretome is enriched with antiproliferative, anti-migratory, and pro-apoptotic factors that act against tumors. This effect of MSCs isolated from prenatal chicks may be significant in the context of the microenvironment of the source of these MSCs. Tumors are not common in the early embryo, suggesting that the embryonic microenvironment, although containing actively proliferating and actively differentiating cells, is non-permissive for tumors. Joel et al., [32] have studied the behavior of human glioblastoma multiforme (GBM) cells in the embryonic tissue microenvironment of the chicken embryo. They found that glioma stem cells enriched from GBM exhibited reduced proliferation and survival, altered gene expression, and did not form tumors within the proliferative embryonic neural tissue. Following a recent report [33], in which the Wnt antagonist DKK1 was shown to inhibit the anti-tumor property of human MSCs, we explored the role of the Wnt- $\beta$-catenin axis in the tumor inhibitory properties of chick BMMSC-CM. At the extracellular level of the Wnt- $\beta$-catenin pathway, addition of the Wnt agonist Wnt 3a, an antibody to the Wnt antagonist sFRP4, and using lithium chloride, the inhibitor of GSK3-ß (required for the phosphorylation of the cytosolic activator of Wnt, i.e., ß-catenin) were able to abolish inhibition. Further, active $\beta$-catenin was reduced and inactive phospho ß-catenin was only observed in the BMMSC-CM-treated U87 cells. Addition of BMMSC-CM also led to the inhibition of the anti-apoptotic genes XIAP and cyclin D1, the angiogenic genes VEGF, the metastasis-associated gene MMP2, but resulted in upregulation of apoptotic genes, caspase-3, p21, and Bax. All these genes are associated downstream of the Wnt- $\beta$-catenin pathway, thereby providing evidence that chick MSC-CM mediated anti-tumor activity could be regulated by Wnt pathway associated genes. Inhibition of angiogenesis of U87 cells by BMMSC-CM also showed clearly an innate tumor nonpermissive ability. In addition, we demonstrate a marked suppression of migration of U87 cells by chick BMM-CM in an in vitro migration assay to provide further evidence of an anti- 
tumor ability of chick BMMSC-CM. Further confirmation of the anti-proliferative effect using a head and neck tumor cell line, suggests that BMMSC-CM inhibition could be effective across multiple types of tumors.

Therefore, chBMMSCs isolated from prenatal bone marrow could also have an innate tumor non-permissive ability that is inhibitory to glioma cells, thereby preventing their proliferation and migration (as seen in the wound scratch assay), and resulting in an increase of apoptotic markers (p21 and Bax) and a decrease in the oncogenic marker, CycD1.

Thus, from the observations in this study, we conclude that BMMSCs derived from prenatal chicken can be used as an easily available and rapidly proliferating stem cell platform to explore factors contributing to pluripotency, stemness, and regulation of multi-lineage differentiation. The anti-tumorigenic potential of the secreted factors from chBMMSCs needs to be further characterized to develop an effective therapeutic against glioblastoma.

\section{ACKNOWLEDGMENTS}

This work was supported by Curtin University Commercialization Advisory Board and School of Biomedical Sciences Strategic Research Funds, and India Initiative funds provided by Prof Arun Dharmarajan.

\section{DISCLOSURE OF INTEREST}

Authors declare no potential conflicts of interest.

\section{REFERENCES}


1. Arthur A, G Rychkov, S Shi, SA Koblar, S Gronthos. (2008). Adult human dental pulp stem cells differentiate toward functionally active neurons under appropriate environmental cues. Stem Cells. 26:1787-1795.

2. Sigurjonsson OE, MC Perreault, T Egeland, JC Glover. (2005). Adult human hematopoietic stem cells produce neurons efficiently in the regenerating chicken embryo spinal cord. Proc Nat Acad Sci U S A. 102:5227-5232.

3. Murrell W, F Féron, A Wetzig, N Cameron, K Splatt, B Bellette, J Bianco, C Perry, G Lee, A Mackay-Sim. (2005). Multipotent stem cells from adult olfactory mucosa. Dev Dyn. 233:496-515.

4. Park TS, ET Zambidis, JL Lucitti, A Logar, BB Keller, B Péault. (2009). Human embryonic stem cell-derived hematoendothelial progenitors engraft chicken embryos. Exp Hematol.37:31-41.

5. Jadlowiec J, D Dongell, J Smith, C Conover, P Campbell. (2005). Pregnancyassociated plasma protein-a is involved in matrix mineralization of human adult mesenchymal stem cells and angiogenesis in the chick chorioallantoic membrane. Endocrinology. 146:3765-3772.

6. Pisati F, M Belicchi, F Acerbi, C Marchesi, C Giussani, M Gavina, S Javerzat, M Hagedorn, G Carrabba, V Lucini, SM Gaini, N Bresolin, L Bello, A Bikfalvi, Y Torrente. (2007). Effect of human skin-derived stem cells on vessel architecture, tumor growth, and tumor invasion in brain tumor animal models. Cancer Res. 67:3054-3063.

7. Khatri M, TD O’Brien, JM Sharma. (2009). Isolation and differentiation of chicken mesenchymal stem cells from bone marrow. Stem Cells Dev. 18: 1485-92.

8. Rengaraj D, YH Zheng, KS Kang, KJ Park, BR Lee, SI Lee, JW Choi, JJ Han. 
(2010). Conserved expression pattern of chicken DAZL in primordial germ cells and germ-line cells. Theriogenology. 765-776.

9. Warrier S, N Haridas, R Bhonde. (2012). Inherent propensity of amnion derived mesenchymal stem cells towards endothelial lineage: vascularization from an avascular tissue. Placenta. 33: 850-858.

10. Mather, J.P. and P.E. Roberts, 1998. Introduction to Cell and Tissue Culture: Theory and Technique. Plenum Press, New York, London.

11. Wang X, H Hisha, S Taketani Y Adachi, Q Li, W Cui, Y Cui, J Wang, C Song, T Mizokami, S Okazaki, Q Li, T Fan, Z Fan, E Ershwin, S Ikehara. (2005). Characterization of mesenchymal stem cells isolated from mouse fetal bone marrow. Stem Cells. 24: 482- 93.

12. Hung SC, NJ Chen, SL Hsieh, H Li, HL Ma, WH Lo. (2002). Isolation and characterization of size-sieved stem cells from human bone marrow. Stem Cells. 20: 249-258.

13. Xiao Y, H Qian, WG Young, PM Bartold. (2003). Tissue engineering for bone regeneration using differentiated alveolar bone cells in collagen scaffolds. Tissue Eng. 9:1167-1177.

14. Seo MJ, SY Suh, YC Bae, JS Jung. (2005). Differentiation of human adipose stromal cells into hepatic lineage in vitro and in vivo. Biochem Biophys Res Commun. 328: 258- 64 .

15. Chen LB, XB Jiang, L Yang. (2004). Differentiation of rat marrow mesenchymal stem cells into pancreatic islet beta-cells. World J Gastroenterol.10:3016-20.

16. Woodbury D, Reynolds K, IB Black IB. (2002).Adult bone marrow stromal stem cells express germline, ectodermal, endodermal, and mesodermal genes prior to neurogenesis. J Neurosci Res. 69:908-17. 
17. Kim BJ, JH Seo, JK Bubien, YS Oh. (2002). Differentiation of adult bone marrow stem cells into neuroprogenitor cells in vitro. Neuroreport. 13:1185-1188.

18. Yang G, J Tian, C Feng, L Zhao, Z Liu, J Zhu. (2012). Trichostatin A Promotes Cardiomyocyte Differentiation of Rat Mesenchymal Stem Cells After 5-Azacytidine Induction or During Coculture With Neonatal Cardiomyocytes Via a Mechanism Independent of Histone Deacetylase Inhibition. Cell Transplantation. 21:985-996.

19. Donovan D, NJ Brown, ET Bishop, CE Lewis .(2001). Comparison of three in vitro human 'angiogenesis' assays with capillaries formed in vivo. Angiogenesis. 4(2):11321.

20. Liang CC, AY Park, JL Guan. (2007). In vitro scratch assay: a convenient and inexpensive method for analysis of cell migration in vitro. Nat Protoc. 2:329-333.

21. Constantinou T, F Baumann, D LacherM, S Saurer, R Friis, A Dharmarajan .(2008). SFRP-4 abrogates Wnt-3a-induced $\beta$-catenin and Akt/PKB signalling and reverses a Wnt-3a-imposed inhibition of in vitro mammary differentiation. J Mol Signal. 3: 10.

22. Martin I, RF Padera , G Vunjak-Novakovic, LE Freed.(1998). In vitro differentiation of chick embryo bone marrow stromal cells into cartilaginous and bone-like tissues. J Orthop Res.16 (2):181-9.

23. Bai C, L Hou, Y Ma, L Chen, M Zhang, W Guan. (2013). Isolation and characterization of mesenchymal stem cells from chicken bone marrow. Cell Tissue Bank. 14:437-51.

24. Abdallah, B. M., \& M Kassem. (2008). Human mesenchymal stem cells: from basic biology to clinical applications. Gene Therapy. 15, 109-116.

25. Al-Nbaheen M, R Vishnubalaji, D Ali, A Bouslimi, F Al-Jassir, M Megges , A Prigione, J Adjaye, M Kassem, A Aldahmash.(2013). Human stromal 
(mesenchymal) stem cells from bone marrow, adipose tissue and skin exhibit differences in molecular phenotype and differentiation potential. Stem Cell Rev.9(1):32-43.

26. Hass R, C Kasper, S Böhm , R Jacobs.(2011).Different populations and sources of human mesenchymal stem cells (MSC): A comparison of adult and neonatal tissuederived MSC. Cell Commun Signal .9:12.

27. Thomson J, J Itskovitz-Eldor, S Shapiro, M Waknitz, J Swiergiel, et al. (1998)Embryonic stem cell lines derived from human blastocysts. Science. 282: 1145

28. Evans MJ and MH Kaufman. (1981) Establishment in culture of pluripotential cells from mouse embryos. Nature. 292: 154-156

29. Gao Y, C Bai, H Xiong, Q Li, Z Shan, L Huang, Y Ma, W Guan. (2013).Isolation and Characterization of Chicken Dermis-Derived Mesenchymal Stem/Progenitor Cells. BioMed Research International. 2013, 626258, 8.

30. Pulukuri SM, B Gorantla, VR Dasari, CS Gondi, JS Rao. (2010). Epigenetic Upregulation of Urokinase Plasminogen Activator Promotes the Tropism of Mesenchymal Stem Cells for Tumor Cells. Mol Cancer Res. 8:1074-1083.

31. Ahn JO, HW Lee, KW Seo, SK Kang, JC Ra, HY Youn. (2013). Anti-Tumor Effect of Adipose Tissue Derived-Mesenchymal Stem Cells Expressing Interferon- $\beta$ and Treatment with Cisplatin in a Xenograft Mouse Model for Canine Melanoma. PLoS One. 8:e74897.

32. Joel M, CJ Sandberg, JL Boulland, EO Vik-Mo, IA Langmoen, JC Glover. (2013). Inhibition of tumor formation and redirected differentiation of glioblastoma cells in a xenotypic embryonic environment. Dev Dyn. 242:1078-93. 
33. Ma S, Liang S, Jiao H, Chi L, Shi X, Tian Y, Yang B, Guan F.(2014). Human umbilical cord mesenchymal stem cells inhibit C6 glioma growth via secretion of dickkopf-1 (DKK1). Mol Cell Biochem. 385(1-2):277-86. 


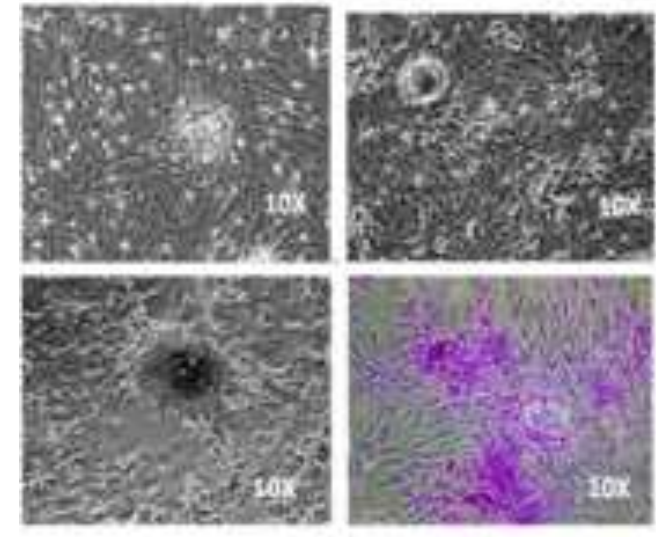

A)

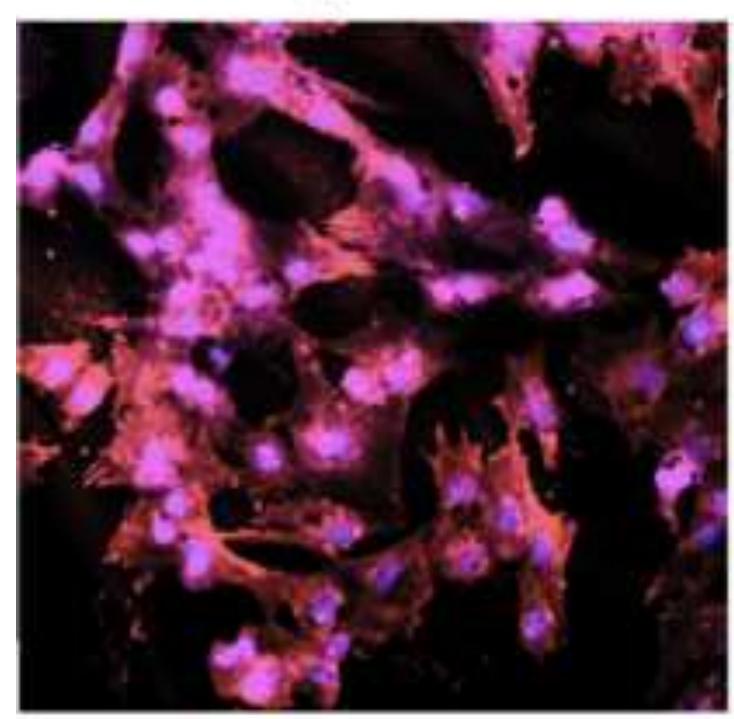

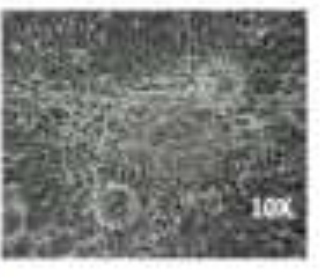

B)

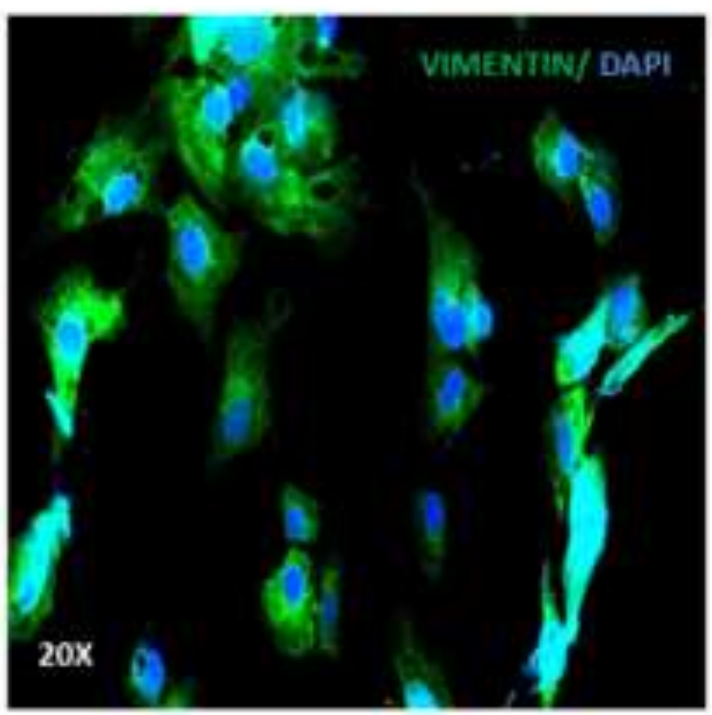

C)
FIGURE 1

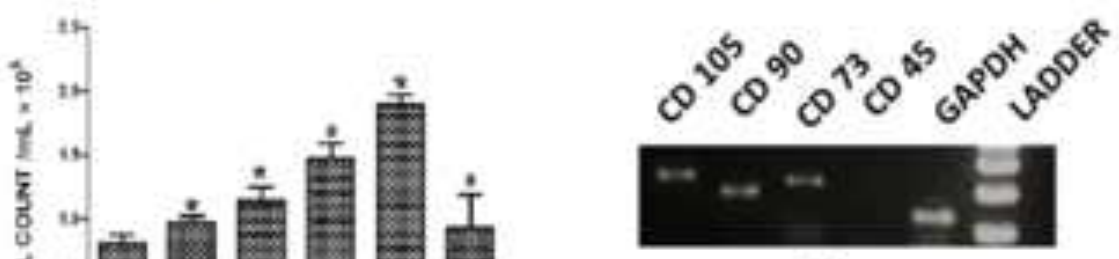

D)

E)
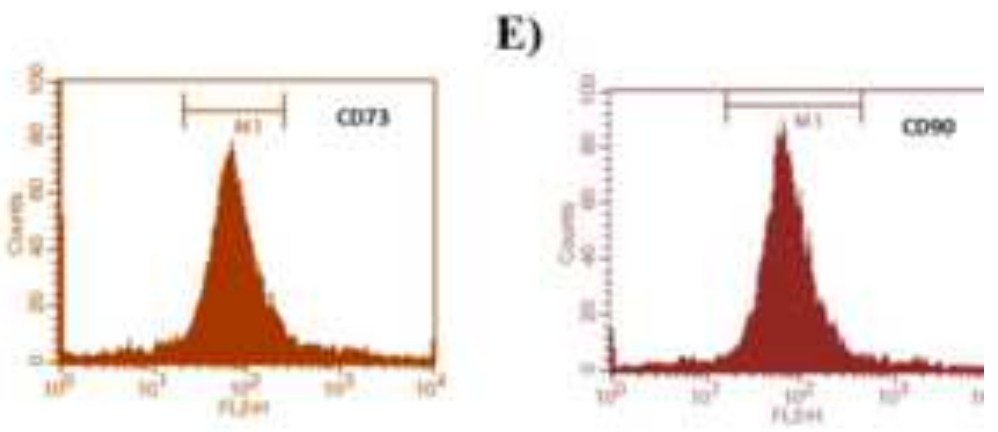

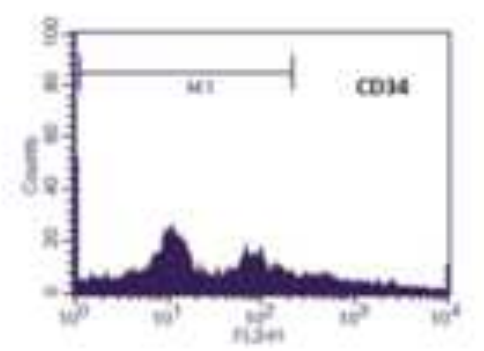


Click here to download high resolution image

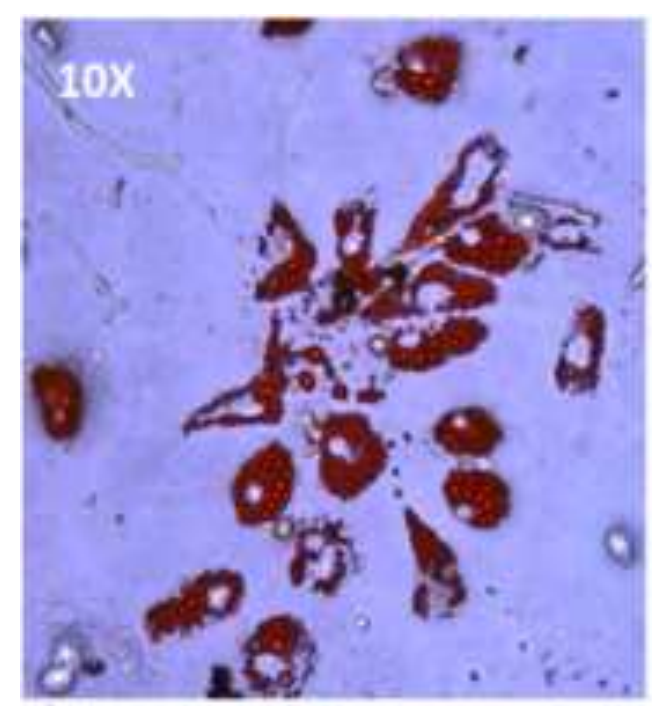

A)

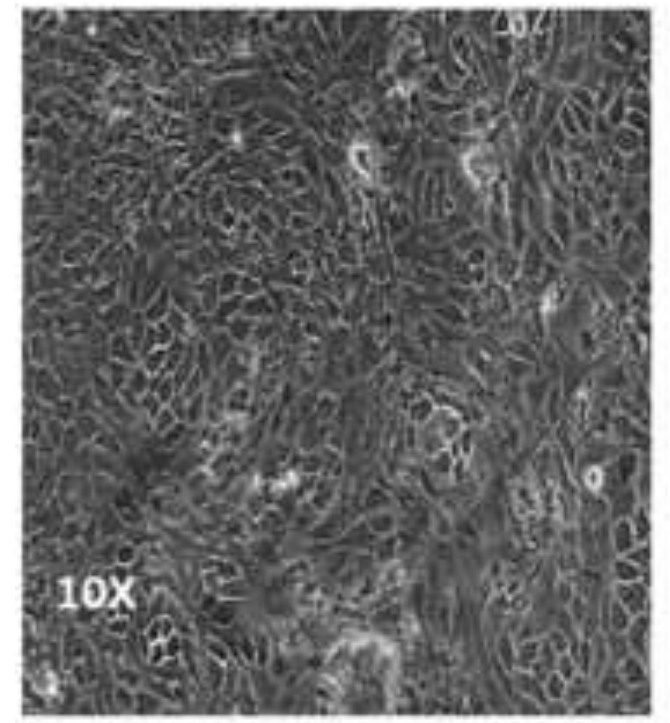

D1

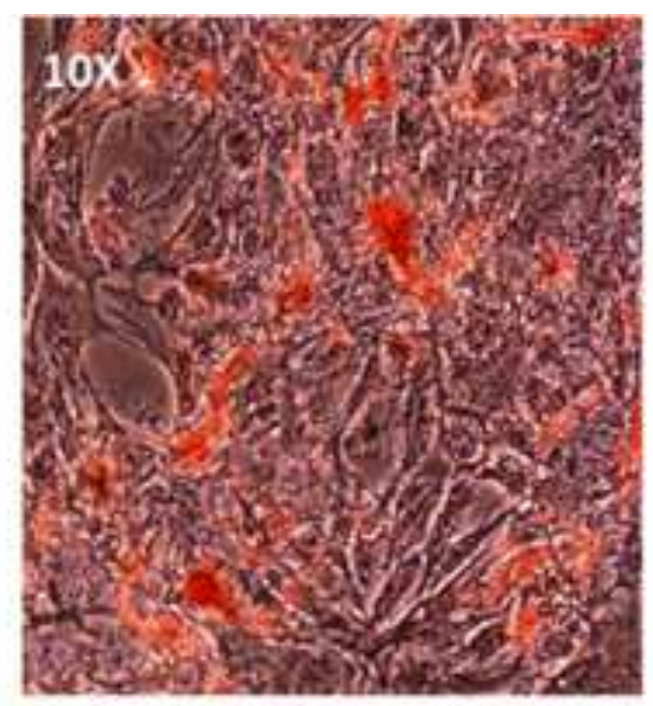

B)

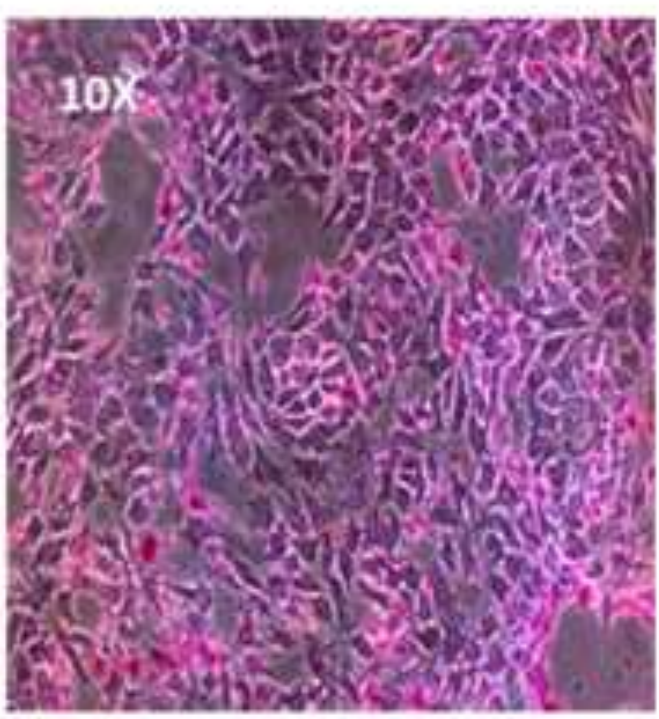

D2

FIGURE 2 A-E

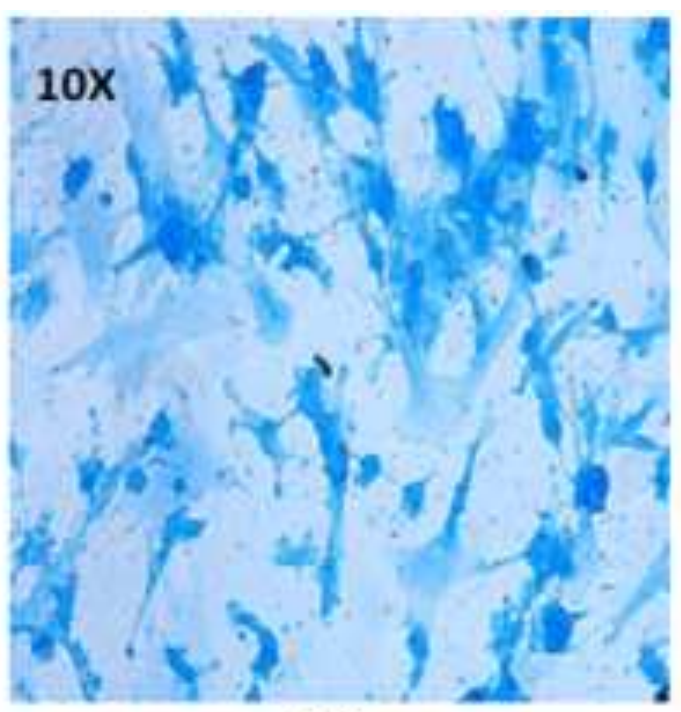

C)

\section{E1}

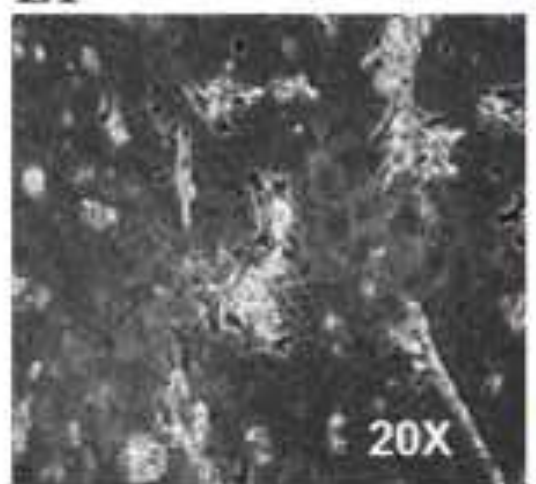

E3

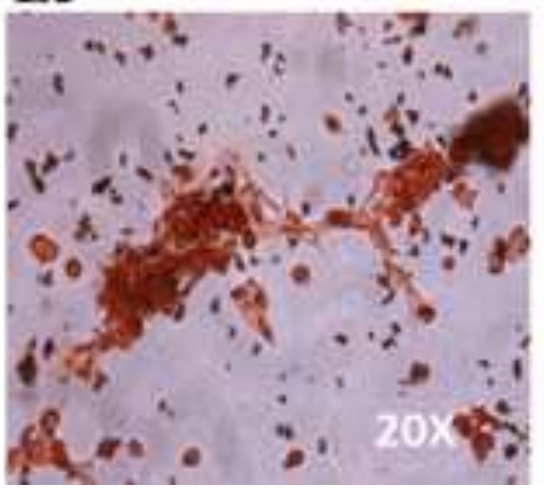

E2

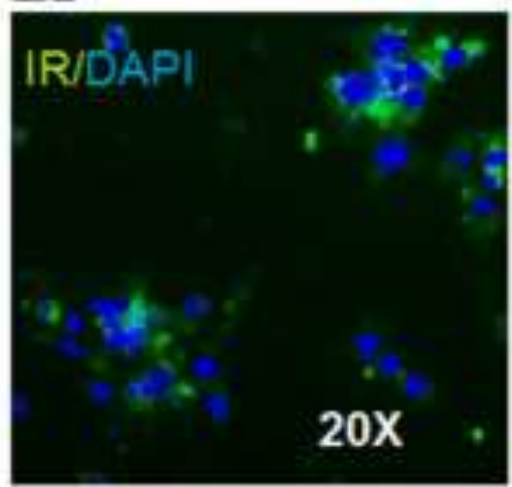

E4

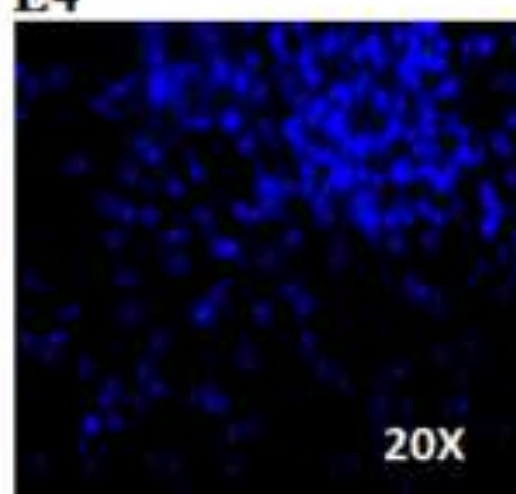


Click here to download high resolution image

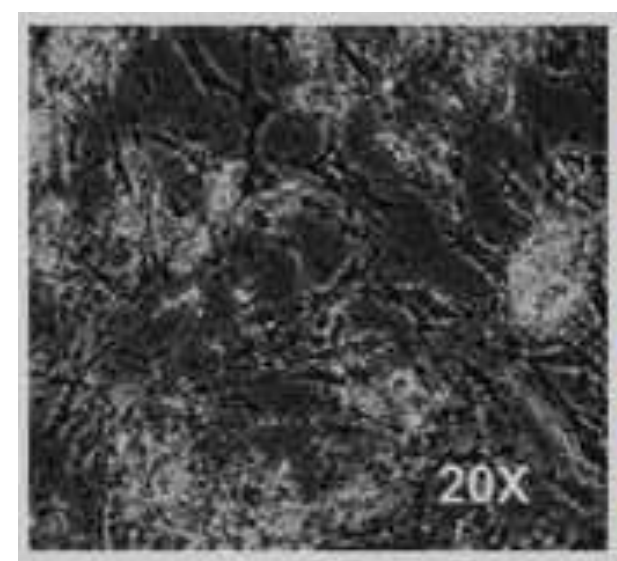

F1

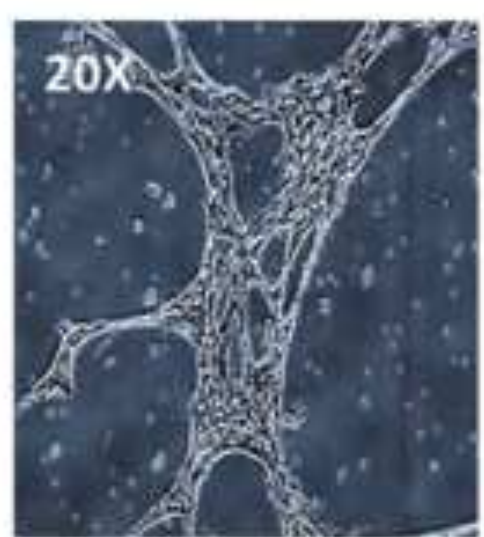

G1

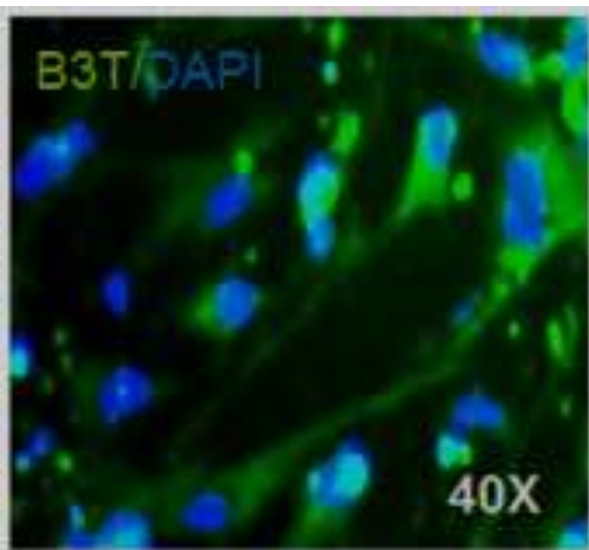

F2

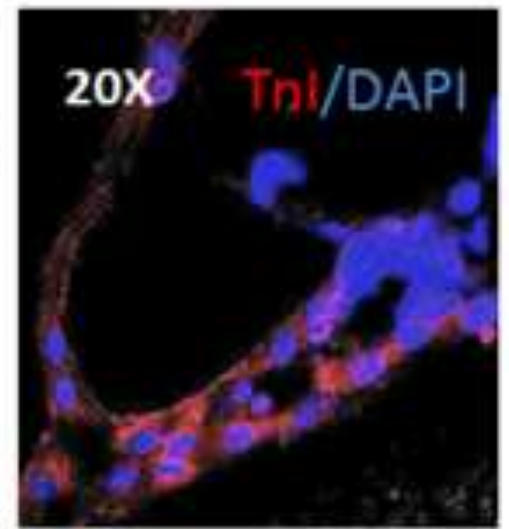

G2

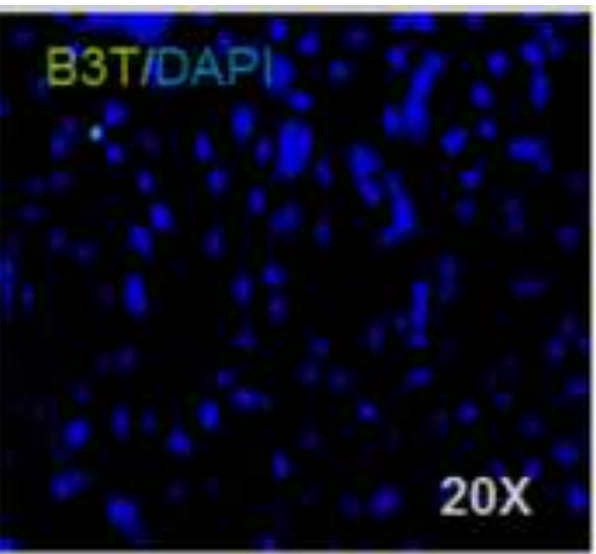

F3
GATA4/DAPI 3

\section{G3}

G4

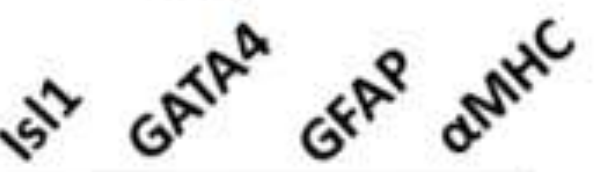

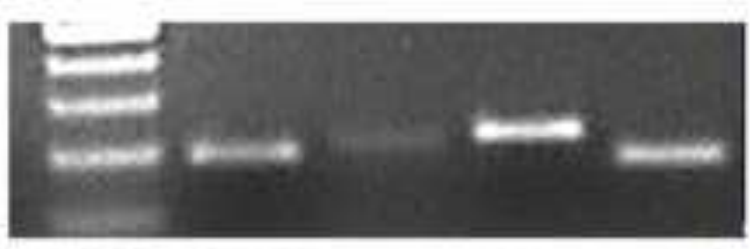

H

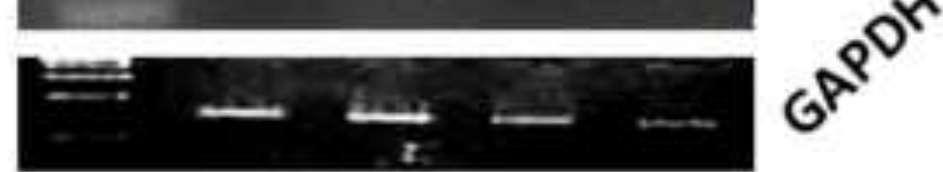

FIGURE 2 F-H 
Figure
Click here to download high resolution image

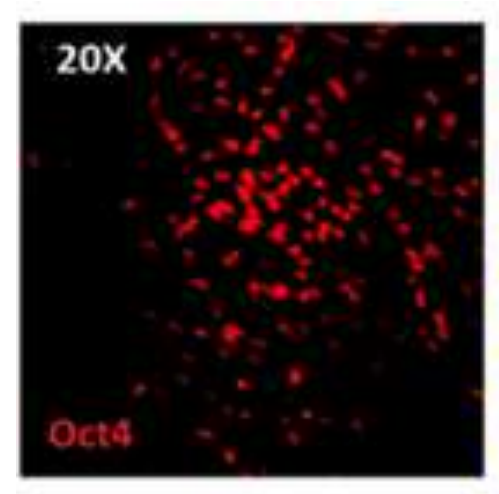

A1

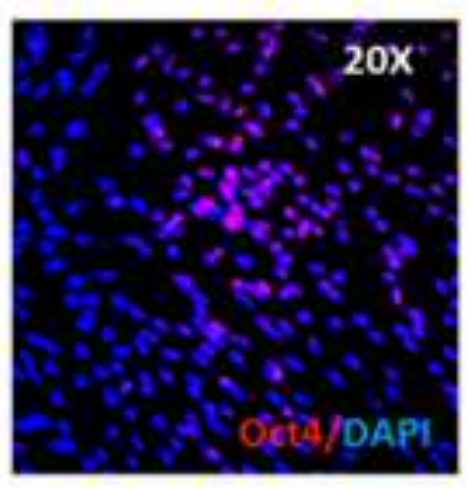

A2

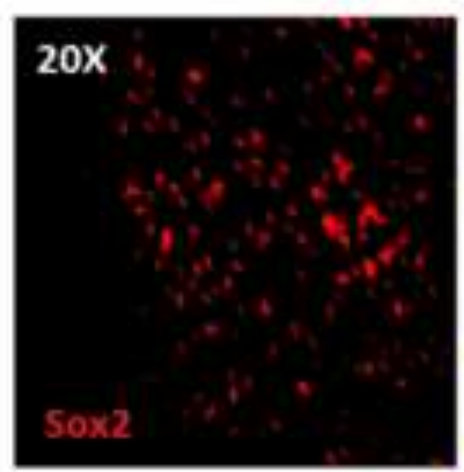

B1

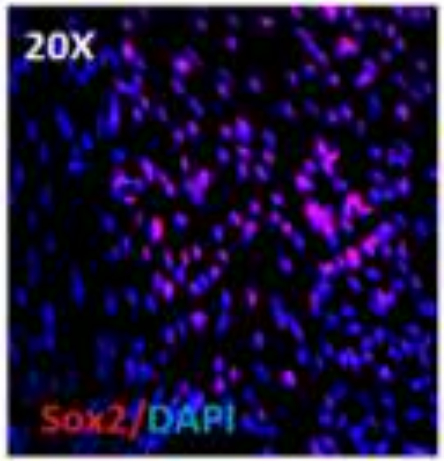

B2

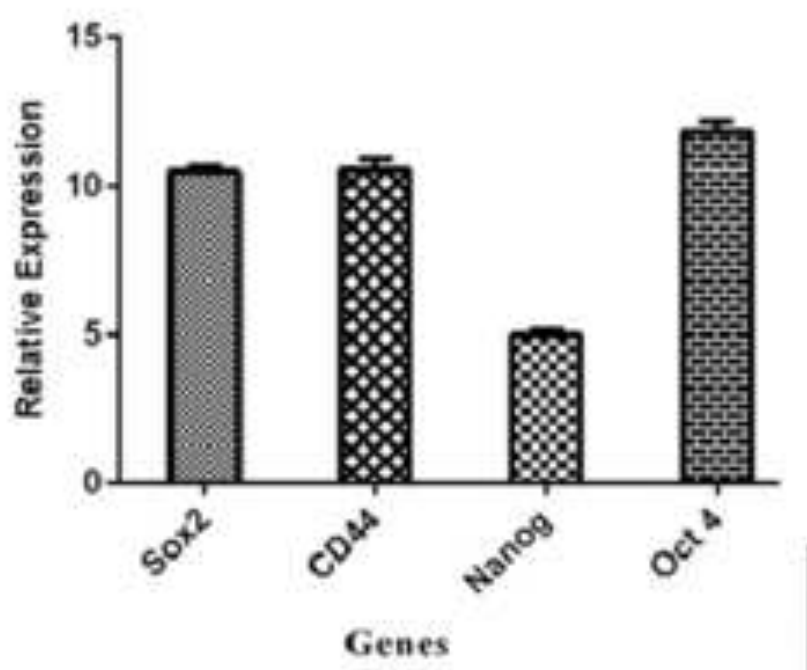

C1

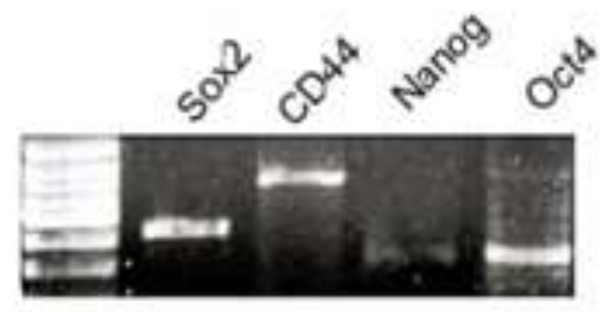

\section{C2}

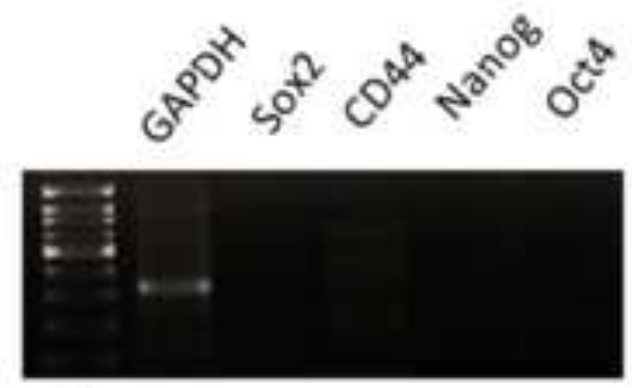

C3

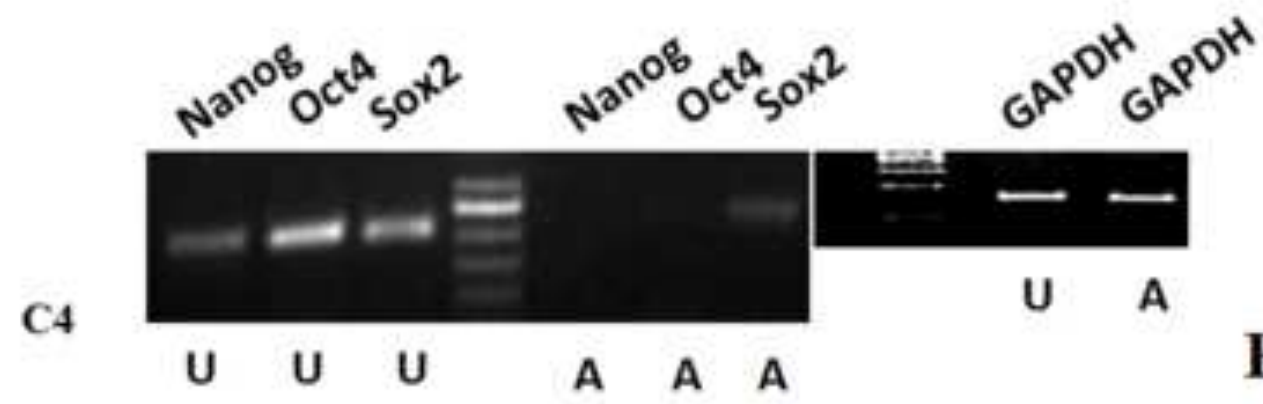

FIGURE 3 


\section{FIGURE 4}
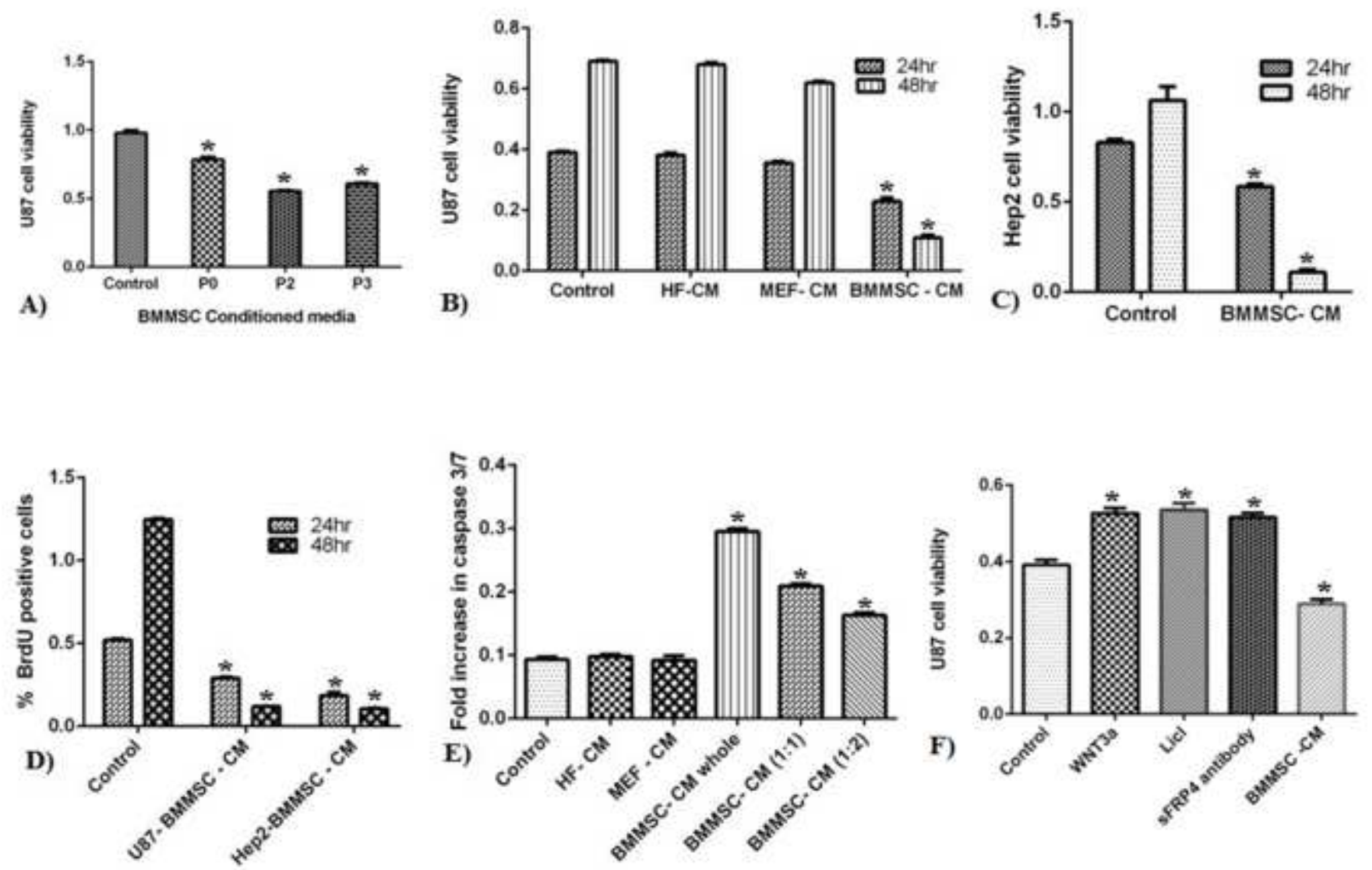
NORMAL MEDIUM

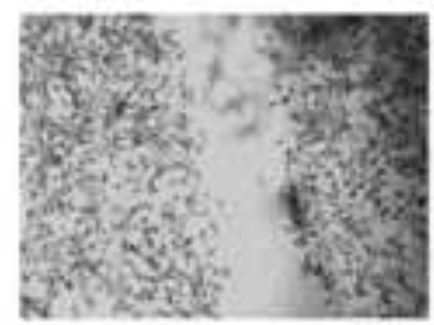

Oh

NORMAL MEDIUM

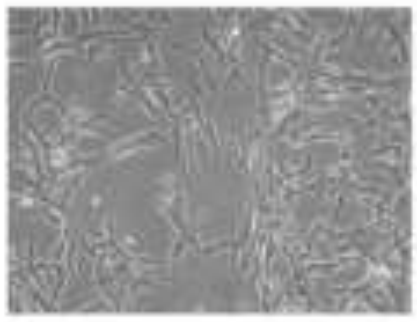

$12 \mathrm{~h}$

NORMAL MEDIUM BMMSC-CONDITIONED MEDIUM

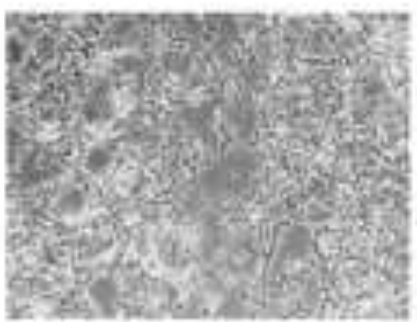

C)

$24 \mathrm{~h}$

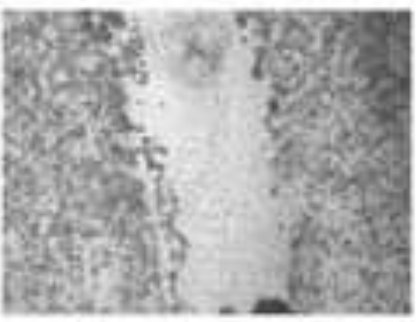

A)

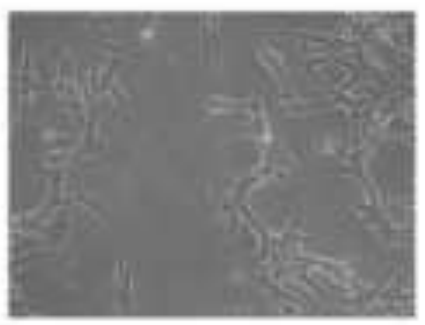

B)

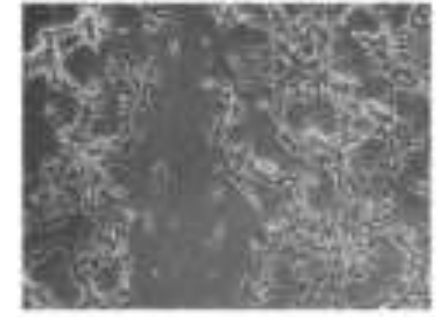

BMMSC- CONDITIONED MEDIUM

BMMSC-CONDITIONED MEDIUM
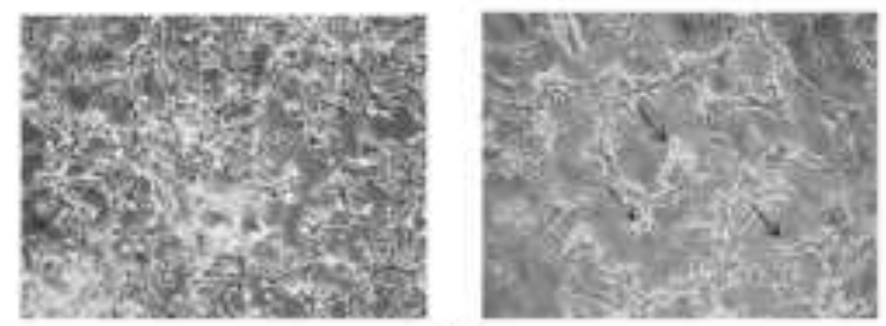

D)

$48 h$

TRANSWELL MIGRATION ASSAY
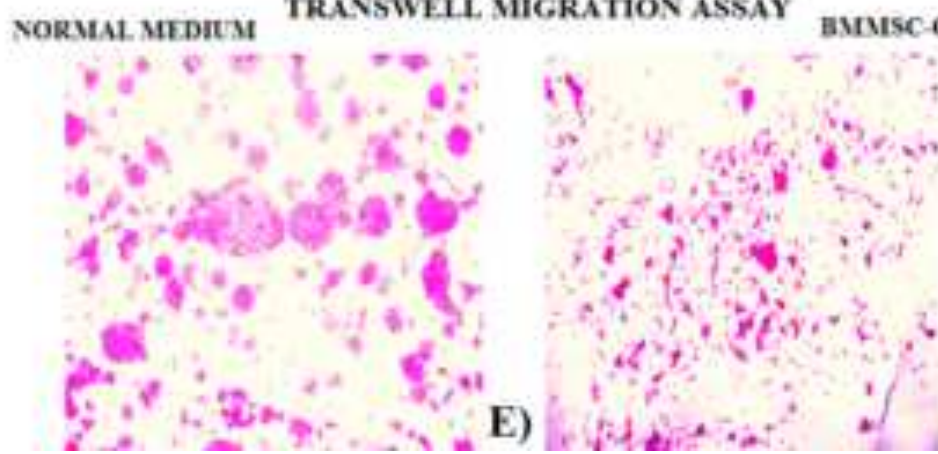

FIGURE. 
NORMAL MEDIUM

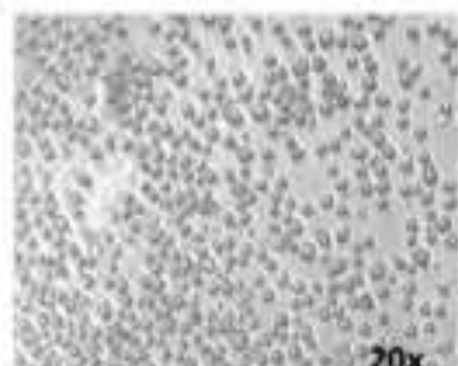

A)

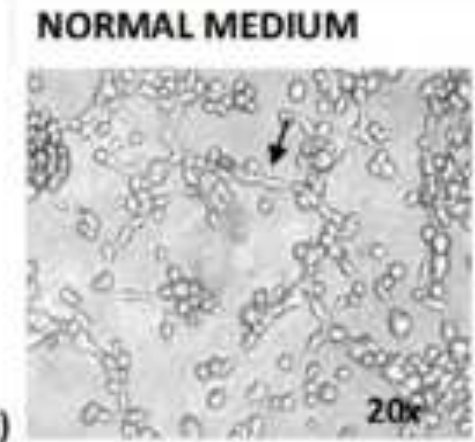

C)
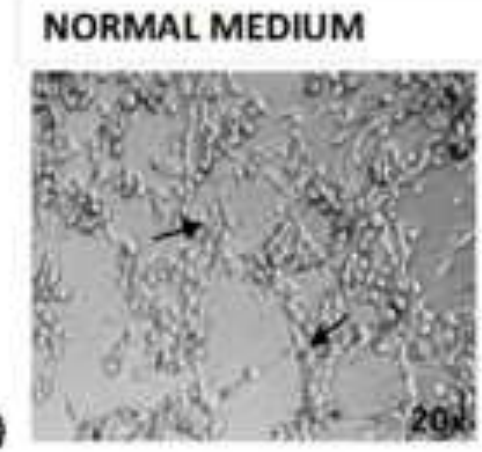

NORMAL MEDIUM

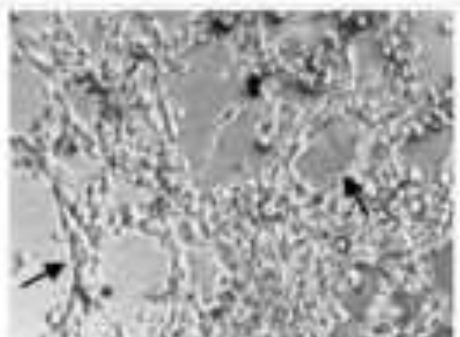

D)

$20 x$
$8 \mathrm{~h}$

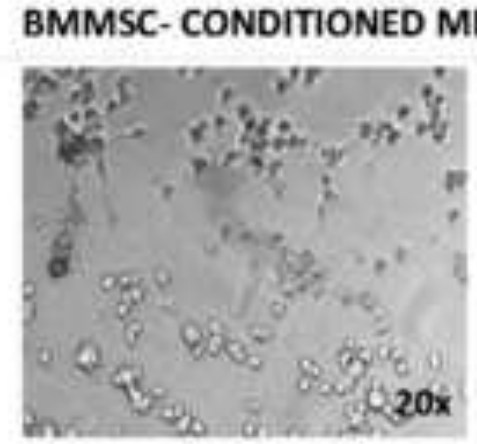

BMMSC- CONDITIONED MEDIUM

BMMSC- CONDITIONED MEDIUM

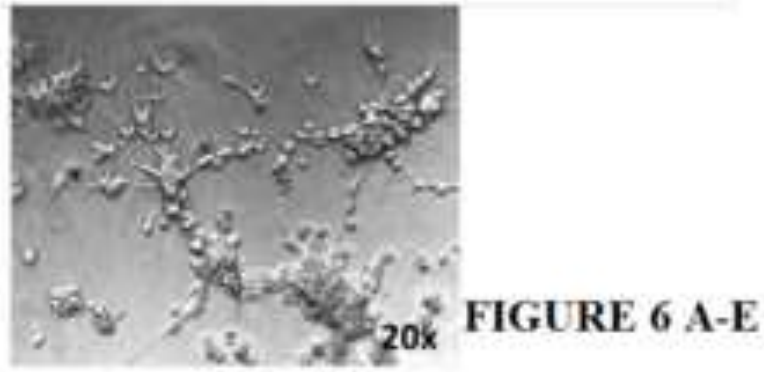

$12 \mathrm{~h}$

BMMSC-CONDITIONED MEDIUM

BMMSC-CONDITIONED MEDIUM

NORMAL MEDIUM

E)

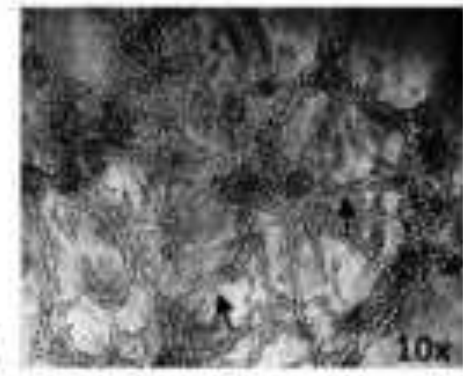

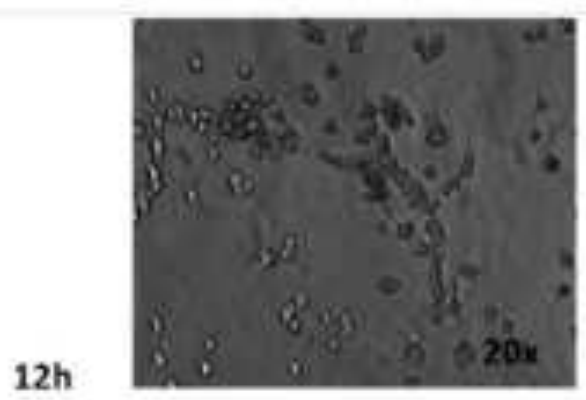
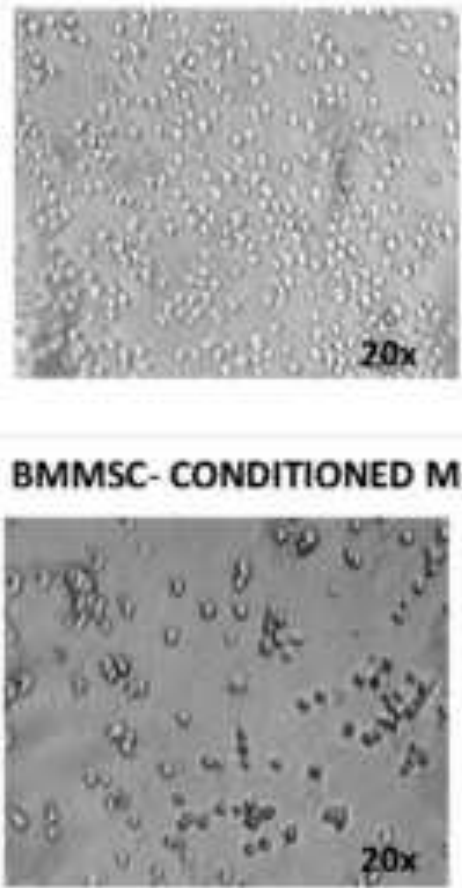

$4 h$

$24 \mathrm{~h}$


TUBE FORMATION IN NORMAL MEDIUM \&H

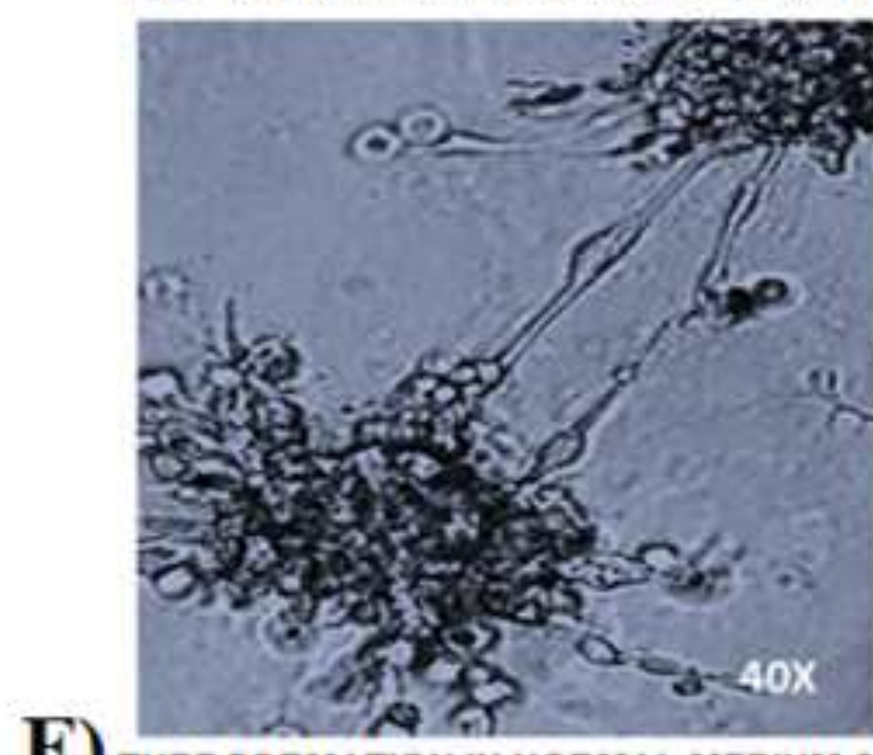

F) TUBE FORMATION IN NORMAL MEDIUM $8 \mathrm{H}$

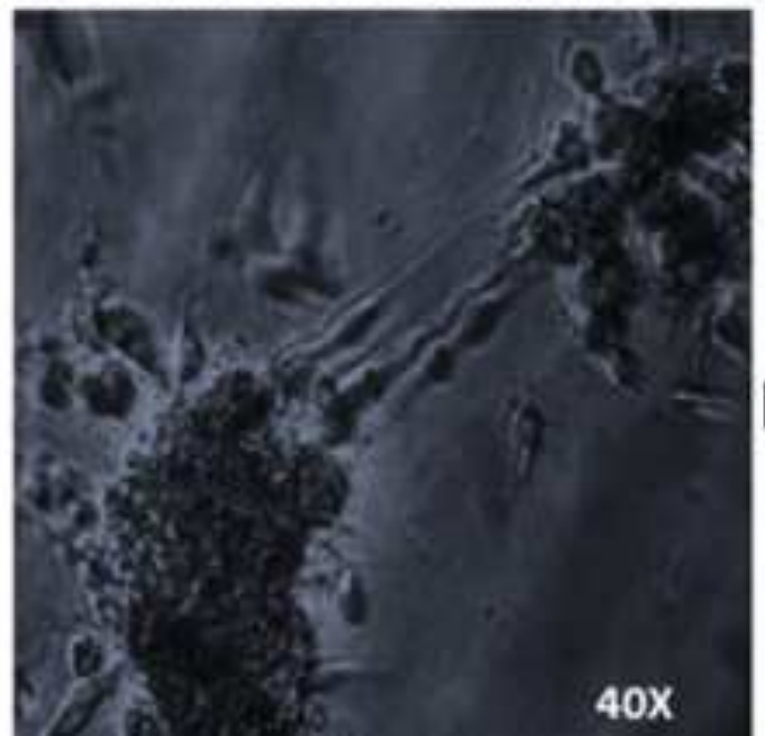

TUBE STRENGTHENING IN NORMAL MEDIUM 24H
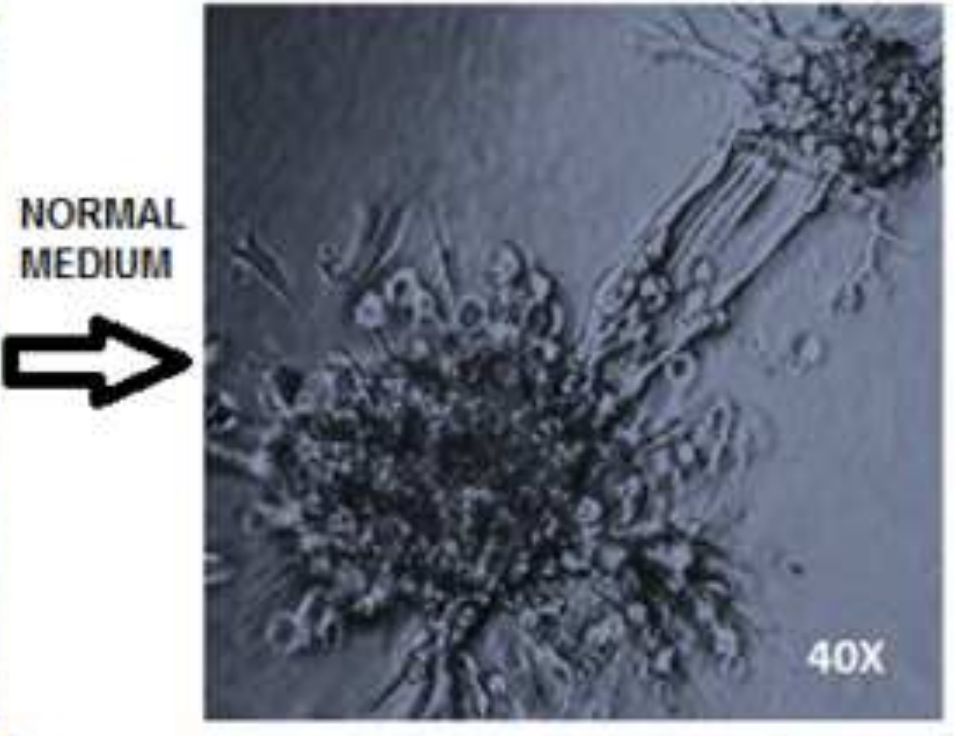

TUBE DISRUPTION IN BMMSC.CM 24H

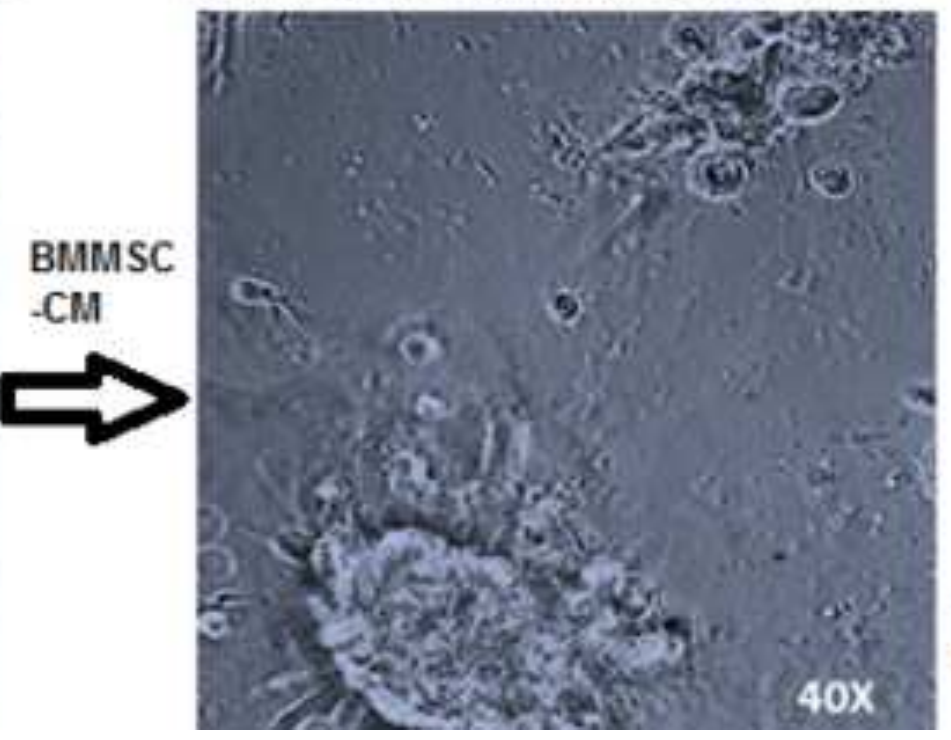




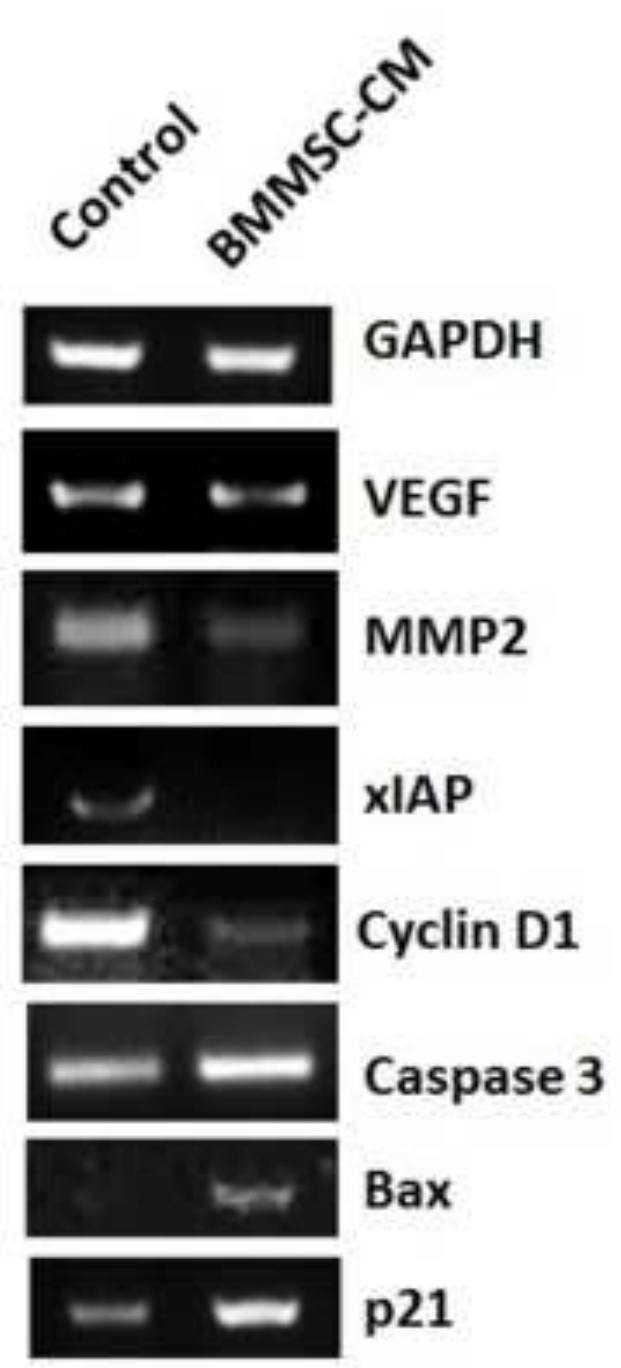

A)

\section{FIGURE 7}

Control

BMMSC -CM
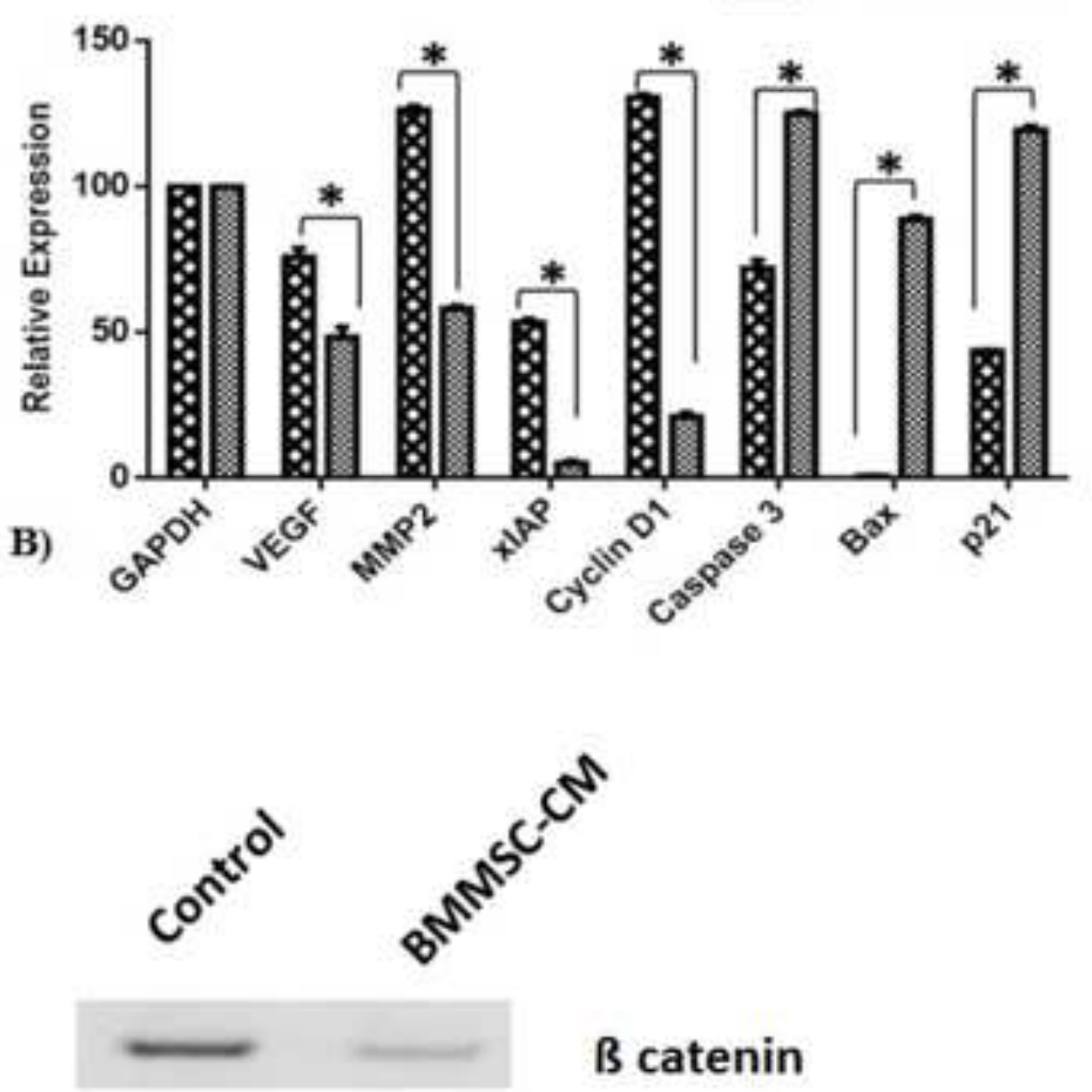

Phospho B catenin

GAPDH

C) 


\section{Figure 1. Characterization of chBMMSCs}

a) Formation of colony forming units and crystal violet stain indicating a colony cluster. The colonies appear as clumps of small fibroblastic cells.

b) Population doubling time was observed at $24 \mathrm{~h}$ and the cells were actively proliferating up to 5 days, after which there was growth inhibition. Results are the mean \pm SD of two independent experiments and in triplicates each (* $\mathrm{p}$ value $<0.01, \mathrm{n}=3$ ).

c) Immunolocalization showing positive staining for $\mathrm{CD} 73$ and vimentin.

d) RT-PCR of CD markers showing expression of MSC markers CD73, 90, and 105, and absence of negative marker CD45.

e) Flow cytometry of CD markers showing CD 73 (96\%), CD 90 (99\%), and no expression of CD 34.

\section{Figure 2. Multilineage differentiation potential of chBMMSCs}

A) Differentiation to the adipocyte lineage was confirmed by staining with Oil red O. Clear lipid secreting globules are seen.

B) and C) Osteocyte differentiation by Von Kossa staining and chondrocyte differentiation by Alcian blue respectively.

D) Differentiation to hepatocyte lineage seen by morphology (D1) and PAS staining (D2).

E) Islet-like cells were observed by cluster-like morphology (e1) and by specific staining for insulin receptor (IR) using immunohistochemistry (E2), by DTZ staining (E3). Lack of islet cells was demonstrated in the undifferentiated MSCs by the absence of IR staining (E4).

F) Neuronal differentiation was seen morphologically by visualization of the axonal processes (F1) and by immunolocalization of the neuron specific marker B-3 tubulin (F2). Lack of neuronal cells was demonstrated in the undifferentiated MSCs by the absence of $B-3$ tubulin staining $(\mathrm{F} 3)$.

G) Cardiomyocyte differentiation was observed by morphological changes such as cellular spreading and formation of multiple junctions. Cardiac specific markers such as the cytoskeletal marker Troponin I (TnI in panel G2) and nuclear marker GATA4 (G3) were observed by immunolocalization using specific antibodies. Lack of cardiac cells was demonstrated in the undifferentiated MSCs by the absence of troponin I staining (G4).

H) Expression of genes specific for islet cells (Isl1), hepatocyte (GATA4), neuronal cells (GFAP), and mature cardiomyocytes ( $\alpha \mathrm{MHC}$ ) were analysed by RT-PCR and showed positive expression in the respective differentiated samples. 
Figure 3. Identification of pluripotent markers in chBMMSCs by immunolocalization and qPCR

A) Staining of Oct 4 using phycoerythrin (magenta) labeled specific monoclonal antibodies (A1) and nuclear localization of Oct4 observed by DAPI stain (A2).

B) Staining of Sox 2 using phycoerythrin (magenta) labeled specific monoclonal antibodies (B1) and nuclear localization of Sox 2 observed by DAPI stain (B2).

C) Quantitation of mRNA expression of pluripotent markers Sox2, Nanog, and Oct 4 and MSC marker CD44 was observed by qPCR. Bar graph represents relative expression of these markers in comparison with GAPDH (c1). Qualitative analysis of the pluripotent markers in chBMMSCs is represented in C2. Lack of expression of these markers is demonstrated in non-stem human fibroblast cells (C3). The high level of expression of the pluripotent markers in undifferentiated BMMSCs $(\mathrm{U})$ is abolished upon adipocyte $(\mathrm{A})$ differentiation $(\mathrm{C} 4)$.

\section{Figure 4: Anti-tumorigenic potential of chBMMSC conditioned media}

A) Proliferation assay showed a clear reduction of U87 cell viability in chBMMSC conditioned media (BMMSC-CM), with the highest inhibition seen in passage 2 cells.

B) Human fibroblast (HF) and mouse embryonic fibroblast (MEF) conditioned media (CM) did not inhibit U87 cells. BMMSC-CM decreased proliferation progressively at $24 \mathrm{~h}$ and $48 \mathrm{~h}$.

C) Proliferation assay showing that BMMSC-CM also inhibited proliferation of Hep2 cells progressively at $24 \mathrm{~h}$ and $48 \mathrm{~h}$.

D) BrdU assay demonstrated a sharp decrease in proliferating U87 cells and Hep2 cells.

E) Apoptotic assay using caspase-3/7 activity showed a clear increase in caspase activity upon BMMSC-CM treatment of U87 cells. Dilution of BMMSC-CM decreased caspase activity, and control CM (HF-CM and MEF-CM) showed no increase.

F) Wnt agonist Wnt3a, GSK3-ß inhibitor lithium chloride ( $\mathrm{LiCl})$, and anti-sFRP4 antibody (antagonist of Wnt) increased proliferation of BMMSC-CM treated U87 cells.

Results are the mean \pm SD of two independent experiments performed in triplicates ${ }^{*} \mathrm{p}$ value $0.05, \mathrm{n}=3$ ).

Figure 5. Wound scratch assay demonstrates the inhibition of proliferation of U87 cells by chBMMSC conditioned medium 
A) Wound was introduced at $0 \mathrm{~h}$ in confluent U87 plates and treated with either control medium or BMMSC- CM. Magnification is at $4 \mathrm{X}$.

B) At $12 \mathrm{~h}$, the wound was partially covered in control whereas in BMMSC conditioned medium treated cells there was no proliferation over the wound area. Magnification is at $10 \mathrm{X}$.

C) At $24 \mathrm{~h}$, in control culture, the wound was fully covered, whereas there was limited proliferation over the wound region in chBMMSC conditioned medium treated cells. Magnification is at $10 \mathrm{X}$.

D) At $48 \mathrm{~h}$, there was rapid proliferation in the untreated cells in contrast to chBMMSC conditioned medium treated cells, where apoptosis of the cells was seen. Arrows indicate cells that have undergone apoptosis. Magnification is at $10 \mathrm{X}$.

E) $H \& E$ stain performed after an in vitro transwell migration assay indicated a marked reduction of cell migration when U87 cells were incubated with chBMMSC conditioned medium. Magnification is at $10 \mathrm{X}$.

Figure 6. In vitro angiogenesis assay elucidates an anti-angiogenic effect of chBMMSC-CM

A) U87 cells (treated for $24 \mathrm{~h}$ with control or BMMSC-CM) were seeded at 0h on a proangiogenic ECMatrix gel pre-coated plate and either control medium or BMMSC-CM was added. Magnification is at 20X.

B) and C) At 4h and 8h, cells incubated in normal medium alone displayed initial processes and tube formation whereas BMMSC-CM treated cells did not proliferate. Magnification is at $20 \mathrm{X}$.

D) At $12 \mathrm{~h}$, capillary tube formation was complete (indicated by arrows) in cells treated with control medium. Growth was sparse in BMMSC-CM treated cells. Magnification is at 20X.

E) At 24h, ring formation of the capillary tubes was prominent in control treated cells (as indicated by arrows) in contrast to BMMSC-CM treated U87 cells in which cells clumped and proliferation was retarded. Magnification is at 10X for control medium-treated cells and at 20X for BMMSC-CM treated cells.

F) Capillary tube formation of U87 cells was induced for $8 \mathrm{~h}$ in control medium (upper and lower left panels). Subsequent incubation with BMMSC-CM or control medium showed a complete disruption of the capillary tubes in BMMSC-CM (lower right panel) in contrast to the control medium, where the capillary tubes were strengthened (upper right panel).

Figure 7. Expression analysis of Wnt-specific and apoptotic markers by qPCR and Western blotting

A) and B) Expression of pro-proliferative and pro-angiogenic markers downstream of Wnt, namely VEGF, MMP2, Cyclin D1, and xIAP was reduced and expression of apoptotic 
markers such as caspase-3, Bax, and p21 was increased in BMMSC-CM treated cells as shown by qPCR (b) and qualitative analysis of these markers.

C) Western blot analysis showed reduced $\beta$-catenin protein levels in U87 cells treated with BMMSC-CM. Phospho ß-catenin was detected only in U87 cells treated with BMMSC-CM. 
Table 1: Primer sequences for pluripotency, MSCs, and differentiation

\begin{tabular}{|c|c|c|c|}
\hline Genes & Primers & $\begin{array}{l}\text { Base } \\
\text { pair }\end{array}$ & $\begin{array}{l}\text { Annealing } \\
\text { temperature } \\
{ }^{\circ} \mathrm{C}\end{array}$ \\
\hline $\begin{array}{l}\text { Chick } \\
\text { GAPDH }\end{array}$ & $\begin{array}{l}\text { F: 5'ATGGCATCCAAGGAGTGA 3' } \\
\text { R: 5'GGGAGACAGAAGGGAACAG 3', }\end{array}$ & 141 & 57 \\
\hline $\begin{array}{l}\text { Chick } \\
\text { Sox } 2\end{array}$ & $\begin{array}{l}\text { F -5’TCC GGC GGT AAT AAT AGC AG 3' } \\
\text { R - 5'TTG CTG ATC TCC GAG TTG TG3' }\end{array}$ & 410 & 54 \\
\hline $\begin{array}{l}\text { Chick } \\
\text { Oct } 4\end{array}$ & $\begin{array}{l}\text { F -5'GCGGTATCTCGAGCCATTCA3' } \\
\text { R -5'TTGTCCGTGTTCTCTGCCTC 3' }\end{array}$ & 390 & 52 \\
\hline $\begin{array}{l}\text { Chick } \\
\text { Nanog }\end{array}$ & $\begin{array}{l}\text { F -5’CAG CAG ACC TCT CCT TGA CC3' } \\
\text { R -5’ CCA GAT ACG CAG CTT GAT 3' }\end{array}$ & 371 & 56 \\
\hline $\begin{array}{l}\text { Chick } \\
\text { CD90 }\end{array}$ & $\begin{array}{l}\text { F- 5'TCAGTGAGAGTGGGGAGAGG 3' } \\
\text { R- 5’TGAGGAGATCAGTGTGGGG 3' }\end{array}$ & 181 & 59 \\
\hline $\begin{array}{l}\text { Chick } \\
\text { CD105 }\end{array}$ & $\begin{array}{l}\text { F:5'CCTGTCCCCATGCTGAATGT3' } \\
\text { R:5'GTTCTGGGGGCTGTTGCTAT3' }\end{array}$ & 303 & 61 \\
\hline $\begin{array}{l}\text { Chick } \\
\text { CD73 }\end{array}$ & $\begin{array}{l}\text { F: 5'GGGCACTCTGGCTTTACTGT3' } \\
\text { R: 5'GGAGGGAGGGGTTCCTGTAT3' }\end{array}$ & 111 & 59 \\
\hline $\begin{array}{l}\text { Chick } \\
\text { CD44 }\end{array}$ & $\begin{array}{l}\text { F-5'GGTTTTATAGTGGGGCATATTGTTATCCC3' } \\
\text { R -5'TTAACCGCGATGCACACGGC 3' }\end{array}$ & 700 & 56 \\
\hline $\begin{array}{l}\text { Chick } \\
\text { CD45 }\end{array}$ & $\begin{array}{l}\text { F-5' GCAGTGTAATGTATGTGCCCG3' } \\
\text { R- 5'TCCTTACGAAGCAGCATGTGT3' }\end{array}$ & 121 & 55 \\
\hline $\begin{array}{l}\text { Human } \\
\text { GAPDH }\end{array}$ & $\begin{array}{l}\text { F-5'GTTAGGAAAGCCTGCCGGTG3' } \\
\text { R-5' AGCATCGCCCCACTTGATTT3' }\end{array}$ & 379 & 55 \\
\hline $\begin{array}{l}\text { Human } \\
\text { Sox2 }\end{array}$ & $\begin{array}{l}\text { F -5'TCAGGAGTTGTCAAGGCAGAG3' } \\
\text { R -5'TCCGGGCTGTTTTTCTGGTT3' }\end{array}$ & 55 & 520 \\
\hline
\end{tabular}




\begin{tabular}{|l|l|l|l|}
\hline $\begin{array}{l}\text { Human } \\
\text { Nanog }\end{array}$ & $\begin{array}{l}\text { F - 5'CCTCCTCCATGGATCTGCTTATTCA3' } \\
\text { R -5' GGAAAGGGACCGAGGAGTA3' }\end{array}$ & 45 & 262 \\
\hline $\begin{array}{l}\text { Human } \\
\text { Oct 4 }\end{array}$ & $\begin{array}{l}\text { F -5'AGGGCAAGCGATCAAGCA3' } \\
\text { R - 5'GGAAAGGGACCGAGGAGTA3' }\end{array}$ & 57 & 600 \\
\hline $\begin{array}{l}\text { Human } \\
\text { MHC 2 }\end{array}$ & $\begin{array}{l}\text { F -5'TTCCGCAAGATCCAGCATGA 3' } \\
\text { R - 5' TTATAAGTGATAGCAACAGAGGGT 3' }\end{array}$ & 57 & 197 \\
\hline $\begin{array}{l}\text { Human } \\
\text { GATA 4 }\end{array}$ & $\begin{array}{l}\text { F -5'GTCTCCAGCCACTCCATCTG 3' } \\
\text { R - 5' GGGTAAGGGCTGGAGTAGGA 3' }\end{array}$ & 60 & 230 \\
\hline $\begin{array}{l}\text { Human } \\
\text { GFAP }\end{array}$ & $\begin{array}{l}\text { F -5'GAGATGGCCCGCCACTTGCG 3' } \\
\text { R - 5' AGCTCTACCGTGAGGCAGCG 3' }\end{array}$ & 60 & 250 \\
\hline $\begin{array}{l}\text { Human } \\
\text { Isl1 }\end{array}$ & $\begin{array}{l}\text { F -5' TGATGAAGCAACTCCAGCAG 3' } \\
\text { R - 5' GGACTGGCTACCATGCTGTT 3' }\end{array}$ & 50 & 214 \\
\hline
\end{tabular}


Table 2. Primer sequences for apoptotic markers- Human

\begin{tabular}{|l|l|l|l|}
\hline Genes & Primers & $\begin{array}{l}\text { Base } \\
\text { pair }\end{array}$ & $\begin{array}{l}\text { Annealing } \\
\text { temperature } \\
\text { 'C }\end{array}$ \\
\hline Bax & $\begin{array}{l}\text { F-5' GCTGGACATTGGACTTCCTC 3' } \\
\text { R-5' } \text { ' }\end{array}$ & 247 & 61 \\
\hline Cyclin D1 & $\begin{array}{l}\text { F-5' AACTACCATCTTCTTCCAGA 3' } \\
\text { R-5' CCACTTGAGCTTGTTCACCA 3' }\end{array}$ & 187 & 61 \\
\hline p21 & $\begin{array}{l}\text { F-5' GAGGCCGGGATGAGTTGGGAGGAG 3' } \\
\text { R-5' CAGCCGGCGTTTGGAGTGGTAGAA 3' }\end{array}$ & 220 & 63 \\
\hline GAPDH & $\begin{array}{l}\text { F-5' CAGAACATCATCCCTGCATCCACT 3' } \\
\text { R-5' GTTGCTGTTGAAGTCACAGGAGAC 3' }\end{array}$ & 181 & 61 \\
\hline Caspase 3 & $\begin{array}{l}\text { F-5'AAGGATCCTTAATAAAGGTATCCATGGAGAACACT3' } \\
\text { R-5'AAAGAATTCCATCACGCATCAATTCCACAATTTCTT3' }\end{array}$ & 322 & 55 \\
\hline MMP2 & $\begin{array}{l}\text { F- 5'CTCTCCTGACATTGACCTTGGCAC 3' } \\
\text { R-5' CTCCAAGGTGCTGGCTGAGTAGATC 3' }\end{array}$ & 142 & 55 \\
\hline xIAP & $\begin{array}{l}\text { F- 5'GGGGTTCAGTTTCAAGGACA3' } \\
\text { R-5' CGCCTTAGCTGCTCTTCAGT3' }\end{array}$ & 183 & 56 \\
\hline VEGF & $\begin{array}{l}\text { F-5' CCTTGCTGCTCTACCTCCAC3' } \\
\text { R-5' CACACAGGATGGCTTGAAGA3' }\end{array}$ & 191 & 59 \\
\hline
\end{tabular}

